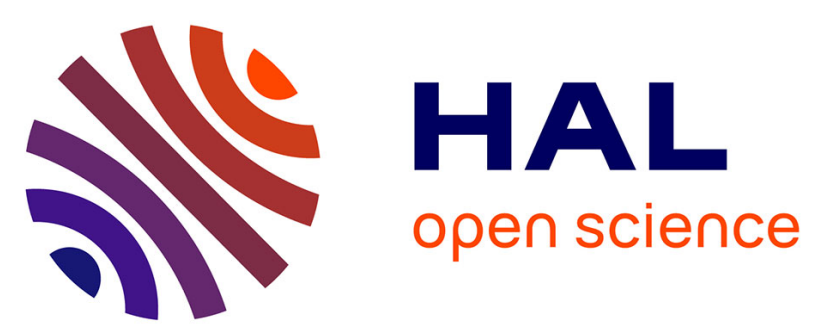

\title{
Path-Average Rainfall Estimation from Optical Extinction Measurements Using a Large-Aperture Scintillometer
}

\author{
R. Uijlenhoet, J.M. Cohard, M. Gosset
}

\section{- To cite this version:}

R. Uijlenhoet, J.M. Cohard, M. Gosset. Path-Average Rainfall Estimation from Optical Extinction Measurements Using a Large-Aperture Scintillometer. Journal of Hydrometeorology, 2011, 12 (5), pp.955-972. 10.1175/2011JHM1350.1 . insu-00649344

\section{HAL Id: insu-00649344 https://hal-insu.archives-ouvertes.fr/insu-00649344}

Submitted on 12 Nov 2021

HAL is a multi-disciplinary open access archive for the deposit and dissemination of scientific research documents, whether they are published or not. The documents may come from teaching and research institutions in France or abroad, or from public or private research centers.
L'archive ouverte pluridisciplinaire HAL, est destinée au dépôt et à la diffusion de documents scientifiques de niveau recherche, publiés ou non, émanant des établissements d'enseignement et de recherche français ou étrangers, des laboratoires publics ou privés. 


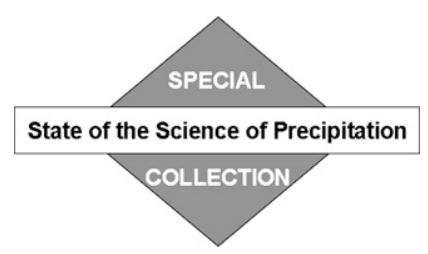

\title{
Path-Average Rainfall Estimation from Optical Extinction Measurements Using a Large-Aperture Scintillometer
}

\author{
R. UIJLENHOET \\ Hydrology and Quantitative Water Management Group, Wageningen University, Wageningen, Netherlands \\ J.-M. COHARD \\ LTHE, UMR 5564 (CNRS, IRD, UJF, INPG), Grenoble, France
}

M. GosSET

GET, UMR 5563 (CNRS, IRD, UPS), Toulouse, France

(Manuscript received 23 August 2010, in final form 9 March 2011)

\begin{abstract}
The potential of a near-infrared large-aperture boundary layer scintillometer as path-average rain gauge is investigated. The instrument was installed over a 2.4-km path in Benin as part of the African Monsoon Multidisciplinary Analysis (AMMA) Enhanced Observation Period during 2006 and 2007. Measurements of the one-minute-average received signal intensity were collected for 6 rainfall events during the dry season and 16 events during the rainy season. Using estimates of the signal base level just before the onset of the rainfall events, the optical extinction coefficient is estimated from the path-integrated attenuation for each minute. The corresponding path-average rain rates are computed using a power-law relation between the optical extinction coefficient and rain rate obtained from measurements of raindrop size distributions with an optical spectropluviometer and a scaling-law formalism for describing raindrop size distribution variations. Comparisons of five-minute rainfall estimates with measurements from two nearby rain gauges show that the temporal dynamics are generally captured well by the scintillometer. However, the instrument has a tendency to underestimate rain rates and event total rain amounts with respect to the gauges. It is shown that this underestimation can be explained partly by systematic differences between the actual and the employed mean power-law relation between rain rate and specific attenuation, partly by unresolved spatial and temporal rainfall variations along the scintillometer path. Occasionally, the signal may even be lost completely. It is demonstrated that if these effects are properly accounted for by employing appropriate relations between rain rate and specific attenuation and by adapting the pathlength to the local rainfall climatology, scintillometerbased rainfall estimates can be within $20 \%$ of those estimated using rain gauges. These results demonstrate the potential of large-aperture scintillometers to estimate path-average rain rates at hydrologically relevant scales.
\end{abstract}

\section{Introduction}

Large-aperture (near infrared) boundary layer scintillometers are becoming standard, commercially available, tools for estimating the turbulent sensible heat flux in the atmospheric surface layer over scales of hydrological and meteorological interest, from a few hundreds of meters to several kilometers (e.g., de Bruin et al. 1995;

Corresponding author address: Remko Uijlenhoet, Hydrology and Quantitative Water Management Group, Wageningen University, P.O. Box 47, 6700 AA Wageningen, Netherlands. E-mail: Remko.Uijlenhoet@wur.nl
Chehbouni et al. 1999; Meijninger and de Bruin 2000; Cain et al. 2001; Lagouarde et al. 2002; Meijninger et al. 2002b; Beyrich et al. 2002). Their measurement principle is based on the estimation of the path-average structure parameter of the refractive index of air from the measured variance of the logarithmic intensity fluctuations (scintillations) of the received signal, which are linearly related to each other under certain conditions (Wang et al. 1978). In general, such scintillations are caused both by temperature and humidity fluctuations. At near-infrared wavelengths, however, the structure parameter of the refractive index of air mainly depends on that of temperature. The sensible heat flux can be 
estimated from the average structure parameter of temperature over the scintillometer path, additional measurements of air temperature, air pressure, and wind speed, as well as from an estimate of the Bowen ratio using the Monin-Obukhov similarity theory (e.g., Meijninger et al. 2002b).

However, apart from the intensity fluctuations of the received optical signal, the average received signal level has a direct hydrometeorological interpretation as well. It has been demonstrated both theoretically (e.g., Atlas 1953; Deirmendjian 1975; Ulbrich and Atlas 1985) and experimentally (e.g., Shipley et al. 1974; Wang and Clifford 1975; Wang et al. 1979; Nedvidek et al. 1983, 1986; Stow et al. 1991; Bradley et al. 2000) that measurements of the path-integrated extinction (attenuation) of optical and near-infrared signals over paths from several hundreds of meters to a few kilometers can be employed to estimate path-average rain rates. The measurement principle is based on the use of a power-law relation to convert the average extinction per unit of pathlength estimated from the link to a path-average rain rate.

Our objective is to demonstrate the potential of standard, commercially available, large-aperture boundary layer scintillometers for path-average rainfall estimation. If feasible, this would imply that such instruments could be employed for the estimation of both path-average sensible heat fluxes (as in Guyot et al. 2009, who employed the same dataset as is used in this article) and path-average rain rates, which would significantly add to their usefulness for hydrology and meteorology.

\section{Rainfall estimation using optical extinction}

\section{a. Measurement principle}

The loss of power of an optical or near-infrared signal traversing rainfall can be described by the Beer-Lambert law of extinction-that is,

$$
P(L)=P_{0}(L) \exp \left[-\frac{\ln 10}{10} \int_{0}^{L} k(s) d s\right],
$$

where $P(\mathrm{~W})$ is the received power in the presence of rainfall, $P_{0}(\mathrm{~W})$ is the power that would be received in the absence of rainfall, $L(\mathrm{~km})$ is the pathlength, $k$ $\left(\mathrm{dB} \mathrm{km}^{-1}\right)$ is the specific extinction coefficient, and $s(\mathrm{~km})$ is the distance from the transmitter. Equation (1) is based on the assumptions that extinction is solely due to rainfall - that is, that the contributions of fog or clouds, water vapor, and aerosols are negligible, and that multiple scattering does not play a role (e.g., Tam 1980; van de Hulst 1981; Tam and Zardecki 1982; Zardecki and Tam
1982). From measurements of the path-integrated extinction between the transmitter and the receiver, the average attenuation per unit of pathlength can be estimated as

$$
\langle k\rangle=\frac{10}{L} \log \left[\frac{P_{0}(L)}{P(L)}\right],
$$

where $P_{0}(L)$ is typically estimated as the signal base level just before the onset of rain.

It has been customary in previous studies to assume a local (i.e., point scale) power-law relation between specific optical extinction $k\left(\mathrm{~dB} \mathrm{~km}^{-1}\right)$ and rain rate $R\left(\mathrm{~mm} \mathrm{~h}^{-1}\right.$ ) of the form $k=c R^{d}$ (see Ulbrich and Atlas 1985, their Table 1, for a list of such relations), such that the path-average rain rate can be estimated from

$$
\langle R\rangle=(\langle k\rangle / c)^{1 / d} .
$$

Apart from the quality of the extinction measurements themselves, the accuracy of this rainfall retrieval method depends on 1) the appropriateness of the coefficients of the employed power-law relation for the microstructure (drop size distribution) of the rain through which the signal propagates and 2) the validity of the tacitly assumed homogeneity of the rainfall macrostructure over the scintillometer path [except for $d \approx 1$, when the relation between $\langle R\rangle$ and $\langle k\rangle$ is approximately linear, such that rain variations along the path do not affect the conversion from $\langle k\rangle$ to $\langle R\rangle$ in Eq. (3)]. Although a detailed analysis of these aspects is beyond the scope of the current study, some of the implications of this assumption will be discussed later; Berne and Uijlenhoet (2007) and Leijnse et al. $(2008,2010)$ present simulation studies of these effects for the case of rainfall estimation using microwave links.

\section{b. Definitions of $k$ and $R$}

The specific attenuation $k\left(\mathrm{~dB} \mathrm{~km}^{-1}\right)$ of an electromagnetic signal traversing a rain region characterized by a drop size distribution $N(D)\left(\mathrm{mm}^{-1} \mathrm{~m}^{-3}\right)$ is defined as (e.g., van de Hulst 1981)

$$
k=\frac{1}{\ln 10} \int_{0}^{\infty} \sigma_{E}(D) N(D) d D,
$$

where $\sigma_{E}(D)\left(\mathrm{cm}^{2}\right)$ is the extinction cross section as a function of the equivalent spherical drop diameter $D(\mathrm{~mm})$. Because of its dependence on the refractive index of water, $\sigma_{E}$ is generally a function of the wavelength of the employed signal and the ambient temperature. For spherical raindrops of arbitrary size, Mie scattering theory describes $\sigma_{E}$ as a function of $D$ (e.g., van de Hulst 1981). 
In the limit where the particle size greatly exceeds the incident wavelength (which holds for optical and nearinfrared signals traversing rain), $\sigma_{E}$ is simply twice the geometrical cross section, independent of the employed wavelength (e.g., Chýlek 1977). As a result, in the optical limit the specific extinction is proportional to the secondorder moment of the raindrop size distribution $N(D)$ :

$$
k=\frac{10^{-2} \pi}{2 \ln 10} \int_{0}^{\infty} D^{2} N(D) d D .
$$

In a similar manner, the rain rate $R\left(\mathrm{~mm} \mathrm{~h}^{-1}\right)$ is defined as

$$
R=6 \pi \times 10^{-4} \int_{0}^{\infty} D^{3} v(D) N(D) d D,
$$

where $v(D)\left(\mathrm{m} \mathrm{s}^{-1}\right)$ is the raindrop terminal fall speed as a function of the equivalent spherical drop diameter $D$. Parameterizations to describe the $v(D)$ relation proposed in the literature range from simple power laws (e.g., Atlas and Ulbrich 1977) to more sophisticated parameterizations, such as the one proposed by Beard (1976).

\section{c. Power-law $k-R$ relations}

The power-law form for the $v(D)$ relation is the only functional form that is consistent with power-law relations between rainfall-related variables, notably between the specific optical extinction coefficient $k\left(\mathrm{~dB} \mathrm{~km}^{-1}\right)$ and rain rate $R\left(\mathrm{~mm} \mathrm{~h}^{-1}\right)$ (e.g., Uijlenhoet 2008). Assuming that the relation between drop diameter and terminal fall speed can be expressed as the power law $v(D)=v_{1} D^{\gamma}$, the rain rate is proportional to the $(3+\gamma)$ th-order moment of $N(D)$ :

$$
R=6 \pi \times 10^{-4} v_{1} \int_{0}^{\infty} D^{3+\gamma} N(D) d D .
$$

The definitions of $k$ and $R$ [Eqs. (5) and (7)] imply that the form of their relationship will depend on the change of the shape of the raindrop size distribution $N(D)$ as a function of the rain rate $R$.

Sempere Torres et al. $(1994,1998)$ have shown that the dependence of the average shape of $N(D)$ on $R$ can be summarized in the form of the scaling-law

$$
N(D, R)=R^{\alpha} g\left(R^{-\beta} D\right),
$$

where $\alpha$ and $\beta$ are scaling exponents and $g(x)$ is a general raindrop size distribution as a function of the scaled drop diameter $x=R^{-\beta} D$, obeying the self-consistency constraints

$$
\alpha+(4+\gamma) \beta=1
$$

and

$$
6 \pi \times 10^{-4} v_{1} \int_{0}^{\infty} x^{3+\gamma} g(x) d x=1 .
$$

Assuming $g(x)$ follows the gamma form $\kappa x^{\mu} \exp (-\lambda x)$ (of which the exponential form $\kappa \exp (-\lambda x)$ is a special case, corresponding to $\mu=0$ ), the latter reduces to

$$
\kappa=\left[6 \pi \times 10^{-4} v_{1} \Gamma(4+\gamma+\mu)\right]^{-1} \lambda^{4+\gamma+\mu} .
$$

Substituting Eq. (8) with the corresponding constraints [Eqs. (9) and (11)] into Eq. (5) leads to the power-law relation

$$
k=c R^{d},
$$

with coefficient

$$
c=\frac{10^{-2} \pi}{2 \ln 10} \int_{0}^{\infty} x^{2} g(x) d x=\frac{10^{-2} \pi}{2 \ln 10} \frac{\kappa \Gamma(3+\mu)}{\lambda^{3+\mu}}
$$

and exponent

$$
d=\alpha+3 \beta=1-(1+\gamma) \beta .
$$

Assuming $v_{1}=3.778$ and $\gamma=0.67$ (Atlas and Ulbrich 1977), these expressions reduce to $c=0.130 \lambda^{1.67}$ (if $\mu=0$, i.e., for exponential raindrop size distributions) and $d=$ $1-1.67 \beta$ (Uijlenhoet et al. 2003a,b). In this manner we have obtained a parameterization for the power-law $k-R$ relation that is fully consistent with the scaling law for the raindrop size distribution.

\section{d. Coefficients of $k-R$ relations}

Values obtained previously for the scaling exponents and the parameters of $g(x)$ for different types of rainfall (e.g., Uijlenhoet 2008) can be used to directly infer the coefficients of the corresponding $k-R$ power laws (Table 1). The significant variation among different precipitation types is associated with systematic differences in the way in which raindrop size distributions change as a function of rain rate. For instance, at a given rain rate, orographic rainfall exhibits smaller mean raindrop sizes and larger concentrations, whereas thunderstorm rainfall is associated with larger mean drop sizes and smaller concentrations (Uijlenhoet 2008). This affects the corresponding power-law $k-R$ relations, which have a significantly larger exponent for orographic rainfall than for thunderstorm rainfall, as well as a coefficient that is an order of magnitude smaller (Table 1). The net 
TABLE 1. Mean values of the parameters $\beta$ and $\lambda$ of the selfconsistent exponential raindrop size distribution (from Uijlenhoet 2008 ) and the corresponding mean values of the $k-R$ coefficients [obtained using Eqs. (13) and (14)] as derived from the $69 Z-R$ relations listed in Battan (1973), stratified according to rainfall type. The category "rest" contains all relations for which an unambiguous identification of rainfall type is impossible.

\begin{tabular}{lcccc}
\hline \hline \multicolumn{1}{c}{ Rainfall type } & $\beta$ & $\lambda$ & $(1 / c)^{1 / d}$ & $1 / d$ \\
\hline Orographic & 0.261 & 8.44 & 0.068 & 1.77 \\
Thunderstorm & 0.185 & 3.53 & 0.911 & 1.45 \\
Widespread-stratiform & 0.189 & 4.20 & 0.596 & 1.46 \\
Showers & 0.321 & 4.15 & 0.487 & 2.16 \\
Rest & 0.202 & 4.21 & 0.582 & 1.51 \\
All & 0.213 & 4.40 & 0.512 & 1.55 \\
\hline
\end{tabular}

result is that, for a given optical extinction, the corresponding rain rate will be much smaller in orographic than in thunderstorm rainfall.

Let us compare the power-law $k-R$ relations derived from the scaling-law formulation for the raindrop size distribution with some relations based directly on measured drop size distributions. A parameterization for $N(D)$ as a function of $R$ that has been widely used in electromagnetic scattering and propagation studies (e.g., Olsen et al. 1978) is the one proposed by Laws and Parsons (1943). Their parameterization consists of eight tabulated mean raindrop size distributions for rain rates of $0.254,1.27,2.54,12.7,25.4,50.8,101.6$, and $152.4 \mathrm{~mm} \mathrm{~h}^{-1}$, obtained from drop size measurements during 1938 and 1939 in Washington, D.C. The main advantage of this parameterization over others proposed in the literature (e.g., Marshall and Palmer 1948) is that it covers a much broader range of rain rates.

Figure 1 shows the relation between the values of $R$ and $k$ (circles) calculated from the eight mean raindrop size distributions of Laws and Parsons (1943) using Eqs. (5) and (6). The coefficients of the corresponding powerlaw $k-R$ relation $\left(R=1.49 k^{1.30}\right.$; bold line) have been determined on the basis of nonlinear least squares regression using $R$ as the dependent and $k$ as the independent variable, because we would ultimately like to employ such relations to estimate $R$ from $k$.

Ulbrich and Atlas (1985) plotted "directly measured" optical extinctions versus rain rates from five different experimental investigations (their Fig. 4) and obtained the logarithmic least squares fit $k=0.91 R^{0.68}$. The inverse of this power-law relation, $R=1.15 k^{1.47}$, is included as the solid line in Fig. 1. This relation follows the one fitted to the Laws-Parsons data very closely for rain rates up to $30 \mathrm{~mm} \mathrm{~h}^{-1}$, above which it tends to overestimate $R$ for a given $k$. The relatively close correspondence between these relations provides confidence in the robustness of the relation derived on the basis of the Laws-Parsons data.

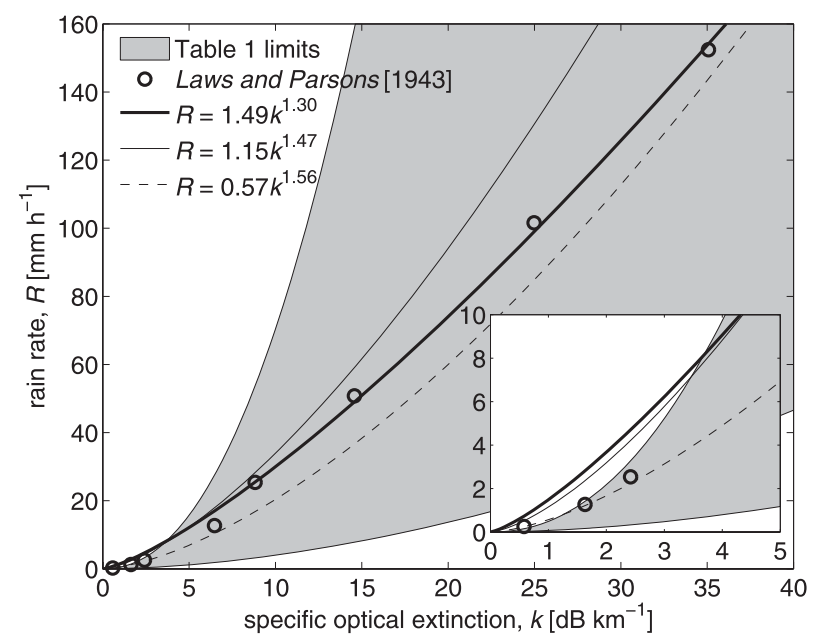

FIG. 1. Rain rate $R\left(\mathrm{~mm} \mathrm{~h}^{-1}\right)$ as a function of specific optical extinction $k\left(\mathrm{~dB} \mathrm{~km}^{-1}\right)$. Circles represent values of $R$ and $k$ computed using Eqs. (5) and (6) for the eight mean raindrop size distributions of Laws and Parsons (1943). The bold curve is power-law relation obtained by nonlinear regression of $R$ on $k$. The solid curve is the inverse of the mean power-law $k-R$ relation obtained by Ulbrich and Atlas (1985). The dashed curve is the inverse of the power-law $k-R$ relation derived from the $N(D)$ parameterization of Marshall and Palmer (1948). Inset are the details of the $k-R$ relations for $R<10 \mathrm{~mm} \mathrm{~h}^{-1}$. The gray area represents the range of the $6 k-R$ power laws from Table 1 .

Marshall and Palmer (1948) proposed an exponential parameterization for the raindrop size distribution$N(D)=N_{0} \exp (-\Lambda D)$, with $N_{0}=8000 \mathrm{~mm}^{-1} \mathrm{~m}^{-3}$ and $\Lambda=4.1 R^{-0.21} \mathrm{~mm}^{-1}$ (later adjusted to $\Lambda=4.23 R^{-0.214}$ by Uijlenhoet and Stricker 1999) —as a fit to average drop size distributions for rain rates between 1 and $23 \mathrm{~mm} \mathrm{~h}^{-1}$ for mostly stratiform rain in Montreal, Canada. This is equivalent to the exponential form of $g(x)$, with $\kappa=8000, \lambda=4.23$, and $\beta=0.214$. Substitution of these values into Eqs. (13) and (14) leads to the power-law relation $k=1.44^{0.64}$ (Ulbrich and Atlas 1985). The inverse of this power-law relation, $R=$ $0.57 k^{1.56}$, is included as the dashed line in Fig. 1. This relation consistently underestimates $R$ for a given $k$ as compared to the one fitted to the Laws-Parsons data, although it provides a closer fit to the actual data points for low rain rates (Fig. 1, inset). In addition, it provides a closer match to the power laws of Table 1, in particular for the categories "widespread-stratiform," "rest," and "all." Of the six $k-R$ power laws in Table 1, the "thunderstorm" relation provides the closest overall fit to the data points in Fig. 1. The lower boundary of the gray area in Fig. 1 corresponds to the "orographic" relation from Table 1, whereas the "showers" relation provides the upper boundary.

The different values in Table 1 and the various curves and the gray area in Fig. 1 provide an idea of the 


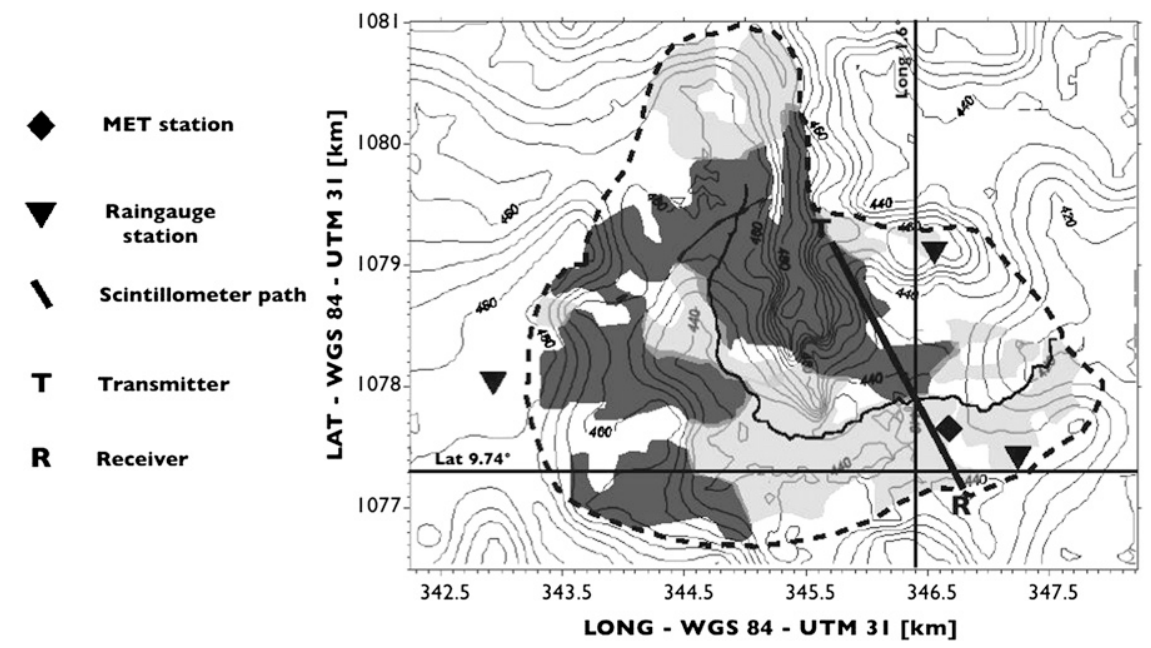

FIG. 2. Experimental setup over the $12 \mathrm{~km}^{2}$ Ara catchment (delineated with the dashed line). The vegetation cover types are differentiated by gray colors on the map; the darker the color, the denser the vegetation. Instruments are indicated with symbols (after Guyot et al. 2009).

uncertainties in rain rate retrievals due to variations in the coefficients of power-law $k-R$ relations associated with differences in rainfall type or climatology. Although these results confirm the strong dependence of rain rate on optical extinction that has been found previously, they also show that the dependence of the power-law coefficients on variations in raindrop size distributions plays a more significant role at optical or near-infrared wavelengths than in the microwave region, for which the associated $k-R$ power laws are much more linear and less dependent on the drop size distribution (e.g., Berne and Uijlenhoet 2007; Leijnse et al. 2008, 2010).

\section{Instrumentation and data processing}

A Scintec near-infrared (880 nm) large-aperture boundary layer scintillometer (BLS900; Scintec 2004) has been installed at an average height of $19 \mathrm{~m}$ above the ground over a path of $2.4 \mathrm{~km}$ (Fig. 2) covering the $12 \mathrm{~km}^{2}$ Ara catchment in Benin as part of the African Monsoon Multidisciplinary Analysis (AMMA) Enhanced Observation Period during 2006 and 2007 (see Guyot et al. 2009 for a detailed description of the experimental setup). Measurements consisted of one-minute-average received intensities from two transmitter disks with 462 light-emitting diodes (LEDs) each (producing a beamwidth of about $8^{\circ}$ ), operating at a pulse repetition rate of $5 \mathrm{~Hz}$ (i.e., 300 samples per minute). Only the signal received from the disk with the largest transmit power has been employed in the subsequent analyses. The received signal was demodulated and digitized to values between 1 and 4095. The resulting average received intensities are available as decimal values between 1.0 (in case of complete loss of signal) and $\sim 950.0$ (in the absence of rain, limited to avoid saturation of the detector), providing a dynamic range of almost $30 \mathrm{~dB}$. After removal of a few sudden drops in the received signal level that are clearly not related to the occurrence of rain (such individual one-minute spikes, exceeding 40 digits, occurred occasionally during the identified events), the power that would be received in the absence of rainfall $\left(P_{0}\right)$ is estimated separately for each of the rainfall events as the maximum received signal level during the event, including part of the dry period preceding the event (with a maximum of $30 \mathrm{~min}$ ). Note that the aerosol concentration in the atmospheric boundary layer varies significantly from the dry season (November to April) to the rainy season (May to October) in this region. The employed procedure to estimate $P_{0}$ for each event separately accounts for such variations in aerosol concentrations, as well as other seasonal variations in the signal extinction not directly related to rainfall.

Although the experiment was designed to estimate turbulent boundary layer fluxes rather than precipitation intensities, data from two tipping-bucket rain gauges installed a few hundreds of meters east of the scintillometer path (Fig. 2) were available for all events as well. These gauges had a temporal resolution of $5 \mathrm{~min}$ and a volume resolution of $0.1 \mathrm{~mm}$ (i.e., an intensity resolution of $1.2 \mathrm{~mm} \mathrm{~h}^{-1}$ ), which makes them less suitable for measuring low rain rates (a well-known issue for tipping-bucket rain gauges).

In addition, one-minute raindrop size distributions obtained from an optical spectropluviometer with a 
surface area of $100 \mathrm{~cm}^{2}$ (Salles et al. 1998), installed about $7 \mathrm{~km}$ east of the scintillometer path, were available for a few events during the rainy season (Moumouni et al. 2008). To avoid possible mismatches between measured drop sizes and velocities, only those drops with fall velocities within a $\pm 40 \%$ band of the theoretical $v(D)$ relation of Beard (1976) have been taken into account (Thurai and Bringi 2005). The measured drop size distributions cover diameters ranging from 0.35 to $7 \mathrm{~mm}$, arranged in classes of $0.35-\mathrm{mm}$ width. To limit the effects of sampling fluctuations (e.g., Uijlenhoet et al. 2006), only those drop size distributions corresponding to rain rates above $0.3 \mathrm{~mm} \mathrm{~h}^{-1}$ have been taken into account.

Individual rainfall events have been identified on the basis of the rainfall measurements from the two tipping-bucket rain gauges. An event is defined as a quasi-continuous period during which the average rain rate from the two gauges is at least $0.6 \mathrm{~mm} \mathrm{~h}^{-1}$, allowing for a maximum gap without rain of $5 \mathrm{~min}$ (corresponding to the time resolution of the gauges). The resulting minimum interevent time is therefore $10 \mathrm{~min}$. The $0.6 \mathrm{~mm} \mathrm{~h}^{-1}$ threshold corresponds to a situation where one of the gauges measures the minimum detectable rain rate of $1.2 \mathrm{~mm} \mathrm{~h}^{-1}$ and the other measures no rain at all. This approach resulted in the identification of 6 rainfall events during the dry season and 16 events during the rainy season.

\section{Results and discussion}

\section{a. Employed $k-R$ relations}

Moumouni et al. (2008) have presented a detailed analysis of the main features of raindrop size distributions observed during the AMMA field campaign with the mentioned optical spectropluviometer installed about $7 \mathrm{~km}$ east of the scintillometer path. From an analysis of 93 rainfall events that occurred between 2005 and 2007 (corresponding to a total rain amount of $1220 \mathrm{~mm}$ ), they concluded that drop size spectra in Benin are well described by gamma distributions with a fixed $\mu$ parameter of 5.5. Combining this value of $\mu$ with the radar reflectivity-rain rate relations derived by Moumouni et al. (2008) and invoking the scaling-law formalism for the raindrop size distribution (as shown in the appendix) leads to three different $k-R$ relations: for all drop size distributions, for the convective distributions only, and for the stratiform distributions only (Table 2).

What is striking when comparing the values in Table 2 with those in Table 1 is that the coefficients of the $k-R$ relations obtained for Benin are much larger than those
TABLE 2. Mean values of the parameters $\beta$ and $\lambda$ of the selfconsistent gamma raindrop size distribution with a fixed value of $\mu=5.5$ and the corresponding mean values of the $k-R$ coefficients [obtained using Eqs. (13) and (14)] as derived from the $Z-R$ relations listed in Moumouni et al. (2008), stratified according to rainfall type.

\begin{tabular}{lcccc}
\hline \hline Rainfall type & $\beta$ & $\lambda$ & $(1 / c)^{1 / d}$ & $1 / d$ \\
\hline Convective & 0.163 & 7.37 & 1.60 & 1.37 \\
Stratiform & 0.167 & 6.45 & 2.19 & 1.39 \\
All & 0.142 & 6.67 & 1.95 & 1.31 \\
\hline
\end{tabular}

based on the $Z-R$ relations listed in Battan (1973), whereas the exponents are somewhat smaller. This implies that, in Benin, relatively small optical extinctions correspond already to significant rain rates or, vice versa, that relatively large rain rates give rise to moderate extinctions. This is related to the fact that all rainfall in Benin is characterized by drop size distributions with a deficit of small drops and therefore relatively low-density rain with large mean drop sizes (Moumouni et al. 2008). Optical extinction, being proportional to the second-order moment of the raindrop size distribution [Eq. (5)], is more sensitive to smaller droplets than rain rate; this is approximately proportional to the 3.67th-order moment [Eq. (7)], which is more sensitive to larger drops. Therefore, the drop size distributions found in Benin give rise to a combination of relatively large rain rates with small optical extinctions. This is expected to reduce the effect of underestimating path-average rain rates due to multiple scattering. Note that the $\lambda$ values in Table 2 are not directly comparable to those in Table 1 because the former are based on a gamma distribution with $\mu=5.5$, whereas the latter are based on a gamma distribution with $\mu=0$ (i.e., an exponential distribution).

The coefficients of the three $k-R$ relations listed in Table 2 will be employed in the subsequent analyses. Ideally, raindrop size distributions measured in the direct vicinity of the scintillometer path during the selected rainfall events should have been employed to infer the coefficients of a dedicated $k-R$ relation. However, as mentioned before, the AMMA scintillometer experiment was designed to estimate sensible and latent heat fluxes rather than rain rates. As such, we have been fortunate enough to obtain a rough idea of the variation of $k-R$ relations in the climate of Benin at all, based on estimated $Z-R$ relations from an optical spectropluviometer located at a distance of about $7 \mathrm{~km}$ from the scintillometer path. A more detailed analysis of $k-R$ relations on the basis of raindrop size distributions measured with this instrument, while beyond the scope of the current study, is a topic of planned investigations. 
(A) optical extinction (15-Jul-2006)

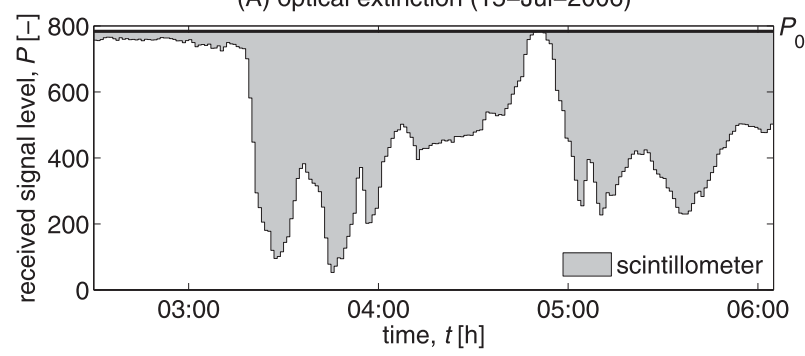

(B) rain rate (15-Jul-2006)

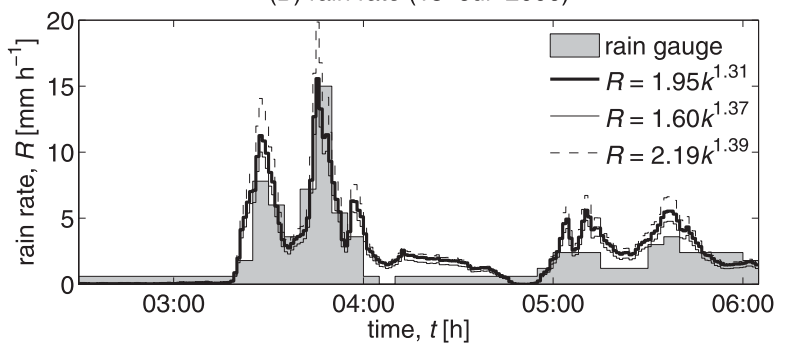

(C) cumulative rain amount (15-Jul-2006)

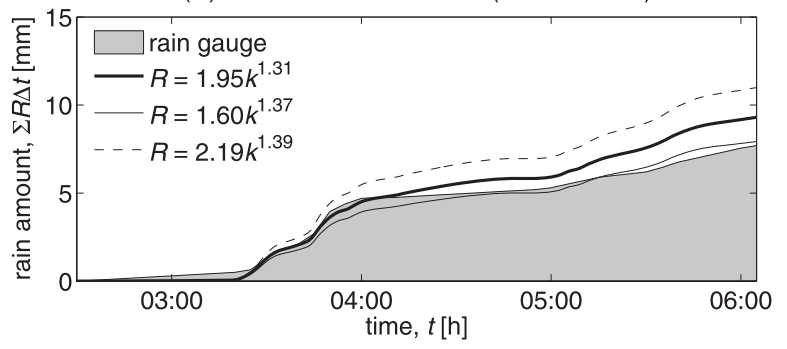

FIG. 3. Path-average (b) rain rates and (c) accumulations estimated using the three $k-R$ power laws presented in Table 2 (bold line $=$ all; solid line $=$ convective; dashed line $=$ stratiform) from the (a) rain-induced attenuation of the received signal (i.e., the difference between the signal base level $P_{0}$ and the one-minuteaverage received signal $P$ ) from a large-aperture scintillometer over a $2.4-\mathrm{km}$ path for an event on $15 \mathrm{Jul} 2006$, as compared with the average rain rate from two nearby tipping-bucket rain gauges.

\section{b. Scintillometer-based rainfall estimates for selected events}

Figure 3 shows time series of the one-minute average received signal from the scintillometer and the inferred path-average rain rates and rainfall accumulations for an event that occurred on 15 July 2006. The gray area in Fig. 3a (i.e., the difference between the signal base level $P_{0}$ and the one-minute average received signal $P$, with $P_{0}$ assumed constant per event but with different values from event to event) indicates the amount of signal attenuation caused by rain intervening on the path between transmitter and receiver. Equation (2) is subsequently used to estimate the optical extinction from the path-integrated signal attenuation. One-minute path-average rain rates (Fig. 3b) and accumulations (Fig. 3c) are computed using

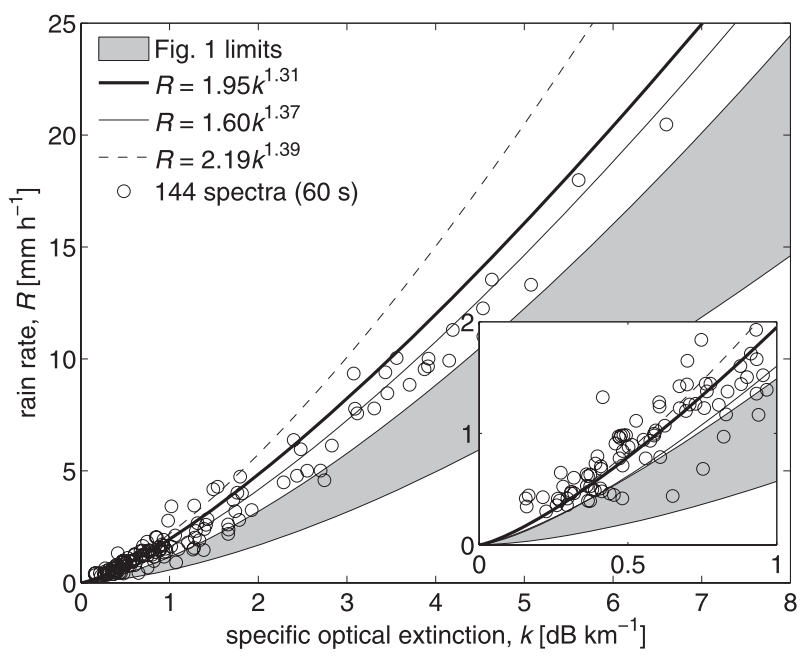

FIG. 4. Rain rate $R\left(\mathrm{~mm} \mathrm{~h}^{-1}\right)$ as a function of specific optical extinction $k\left(\mathrm{~dB} \mathrm{~km}^{-1}\right)$. Circles represent values of $R$ and $k$ computed using Eqs. (5) and (6) for the raindrop size distributions measured on $15 \mathrm{Jul} 2006$ with an optical spectropluviometer located at a distance of about $7 \mathrm{~km}$ from the scintillometer path. Lines are the $k-R$ power laws presented in Table 2 (bold line $=$ all, solid line $=$ convective, and dashed line $=$ stratiform). Inset are the details of the $k-R$ relations for $R<2 \mathrm{~mm} \mathrm{~h}^{-1}$. The gray area represents the range of the three $k-R$ power laws from Fig. 1.

the three $k-R$ relations presented in Table 2. These are compared to five-minute average rain rates and accumulations (gray areas in Figs. 3b,c) from the two tippingbucket rain gauges located in the vicinity of the path between transmitter and receiver (Fig. 2).

Although all three $k-R$ relations yield rain rates that capture the temporal dynamics of the event quite well (Fig. $3 \mathrm{~b}$ ), the convective $k-R$ relation outperforms the other two relations (stratiform and overall), particularly in terms of cumulative rainfall (Fig. 3c). This makes sense given the fact that this event occurred during the monsoon season, which is characterized by a strong presence of convective activity. The good rain rate estimates obtained with the scintillometer on the basis of the convective $k-R$ relation are confirmed by Fig. 4 , which shows that the convective relation indeed nicely captures the variation in the individual $(R, k)$ pairs deduced directly from the measured raindrop size distributions during the 15 July 2006 event (at a distance of about $7 \mathrm{~km}$ from the scintillometer path), in particular for larger rain rates. Moreover, Fig. 5 shows that, on a 5-min basis, the bias and scatter of the rain rates obtained from the scintillometer with respect to those from the two rain gauges is even less than the bias and scatter of one of the gauges with respect to the other.

However, results are not always as good. Figure 6 shows the measured signal attenuations and derived rain rates for an event that occurred on 14 February 2006. 
(A) 5-minute rain rates (15-Jul-2006)

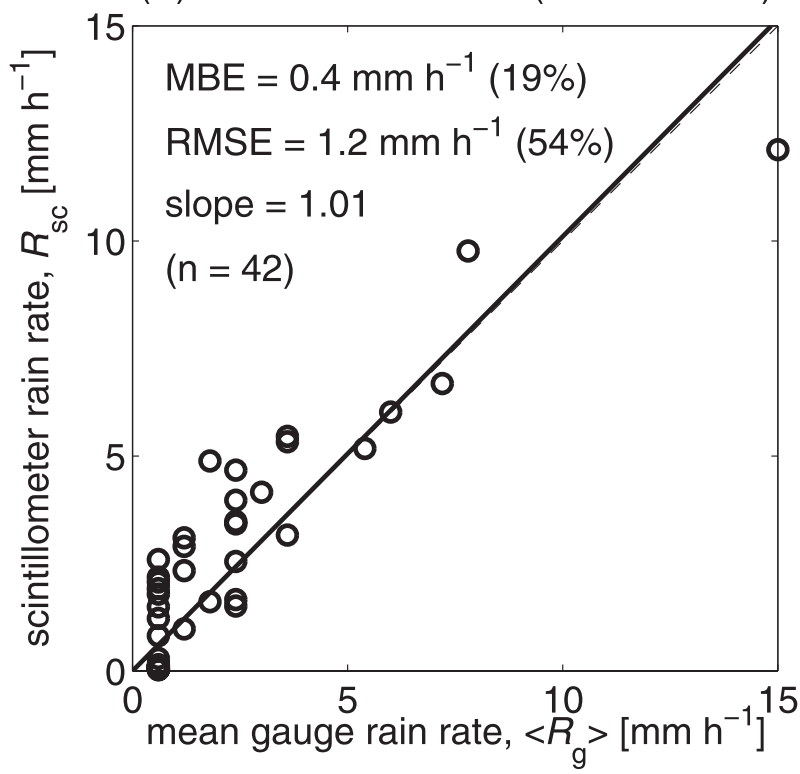

(B) 5-minute rain rates (15-Jul-2006)

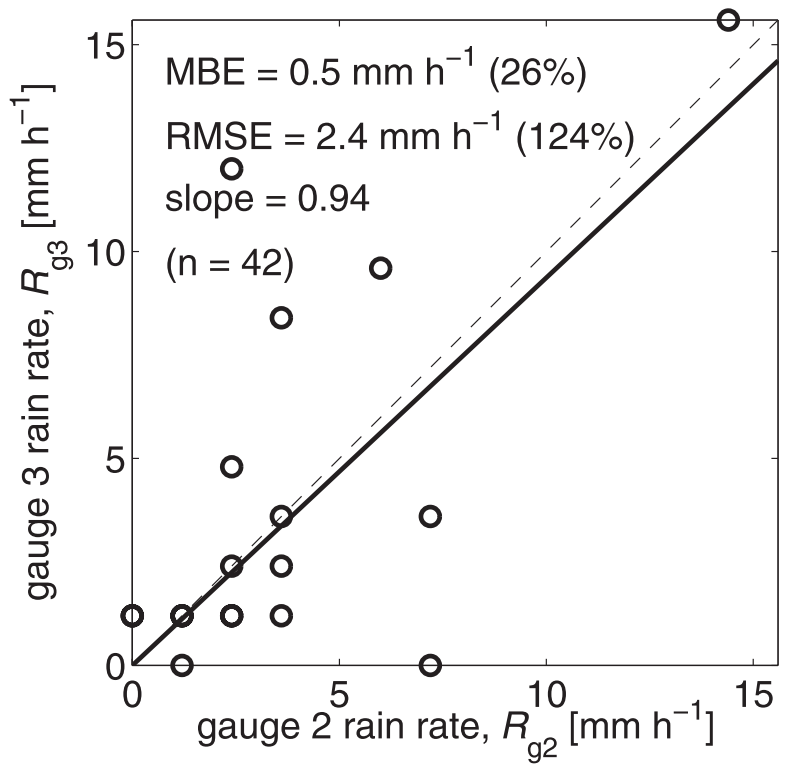

FIG. 5. Comparison of 5-min average rain rates from the scintillometer (using the overall $k-R$ relation from Table 2) with (a) the average from two nearby tipping-bucket rain gauges and (b) comparison of 5-min average rain rates between the two individual gauges for the event on $15 \mathrm{Jul} 2006$ (Fig. 3). The dashed line indicates the 1:1 line; $\mathrm{MBE}=$ mean bias error, absolute and relative to the mean gauge rain rate in (a) or to the mean gauge 2 rain rate in (b); RMSE = root-mean-square error, absolute and relative to the mean gauge rain rate in (a) or to the mean gauge 2 rain rate in (b); slope $=$ slope of a linear regression through the origin of the variable on the $y$ axis to that on the $x$ axis (bold line); and $n=$ number of data points.
(A) optical extinction (14-Feb-2006)

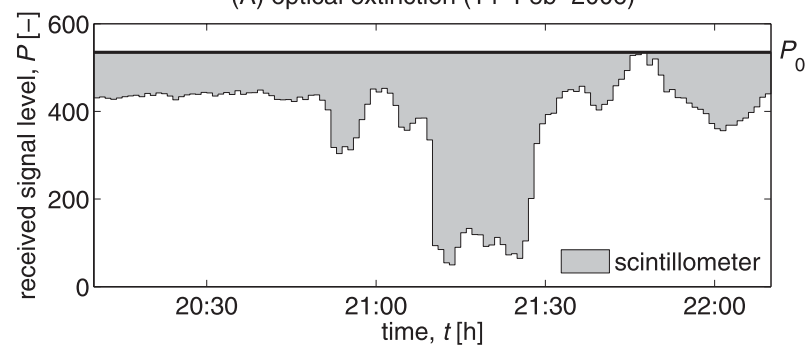

(B) rain rate (14-Feb-2006)

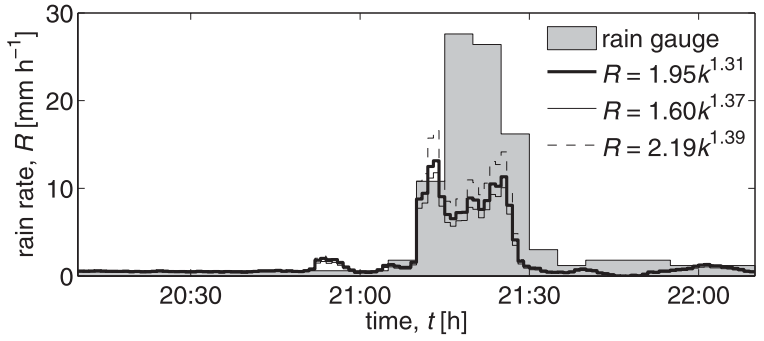

(C) cumulative rain amount (14-Feb-2006)

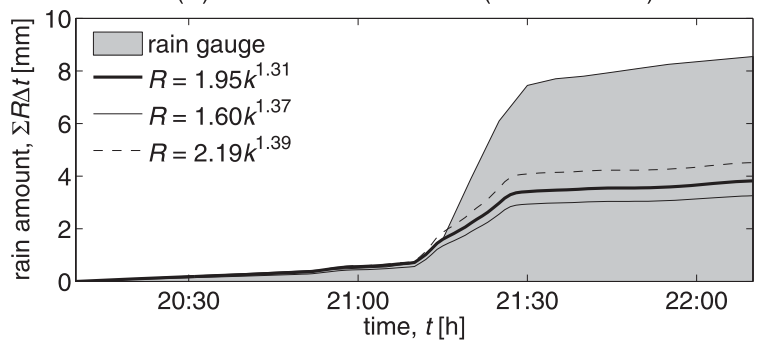

FIG. 6. As in Fig. 3, but for an event on 14 Feb 2006.

This figure demonstrates that, although the rainfall event is clearly detected by the scintillometer, the rain rates derived from the measured optical extinctions systematically underestimate the average rain rates from the two gauges, independent of the employed power-law $k-R$ relation. Additional analyses (not shown here) indicate that this systematic underestimation remains when the scintillometer is compared to each of the two gauges separately, suggesting that spatial rainfall variation along the scintillometer path does not play a significant role here. This leaves an inappropriate $k-R$ relation and/or an ill-defined signal base level $P_{0}$ as the only remaining explanations for the observed deviation. Apparently, neither of the employed $k-R$ relations properly reflects the rainfall microstructure exhibited by this event. Unfortunately, the optical spectropluviometer was not installed until June 2006, so we have no way of verifying this hypothesis. Note, however, that this was the first event of the year after a four-month dry period. The atmospheric boundary layer was loaded with a high aerosol concentration from the Sahel during the day. In addition, a southwesterly monsoon flux brought humidity to the 
(A) optical extinction (15-Feb-2006)

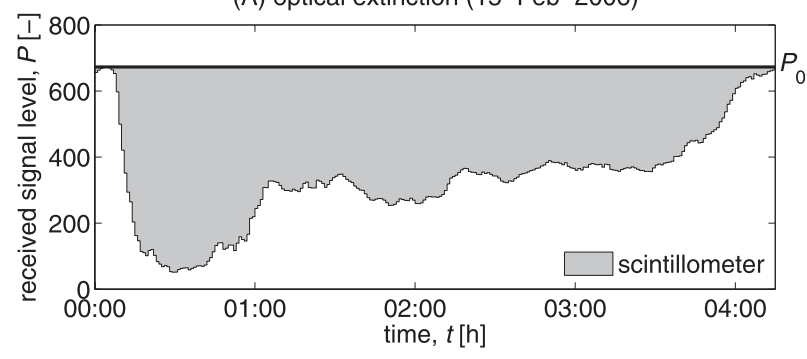

(B) rain rate (15-Feb-2006)

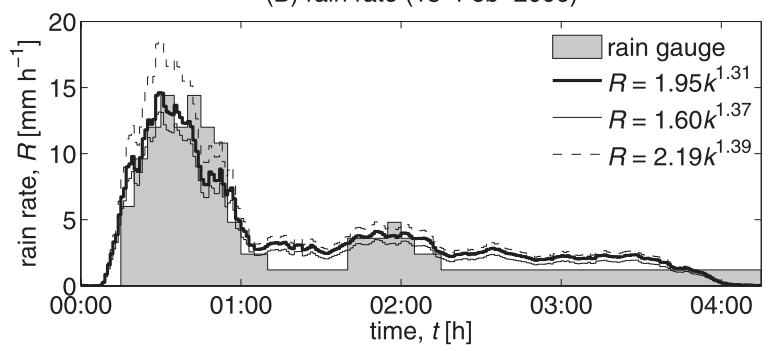

(C) cumulative rain amount (15-Feb-2006)

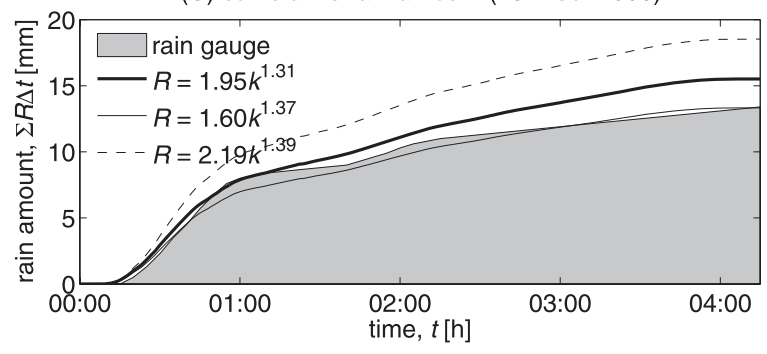

FIG. 7. As in Fig. 3, but for gauge 2 on 15 Feb 2006.

lower layers of the atmosphere during the night preceding the rainfall event. These conditions produced significant variations in aerosol concentrations and thermodynamic conditions during the event, which make it difficult to interpret because of possible variations in the signal base level during the event that were not properly accounted for.

The effect of spatial rainfall variation along the scintillometer path is clearly visible when comparing Fig. 7 and Fig. 8. These figures show the signal attenuations suffered by the scintillometer and the inferred rain rates for the event on 15 February 2006 as compared to the rain rates measured by each of the two tipping-bucket rain gauges. While the scintillometer seems to do a good job compared to gauge 2, in particular for the rainfall maxima around 00:30 and 02:00 h (Fig. 7), it severely underestimates the first rain rate peak measured by gauge 3 (Fig. 8). This shows that 5-min rain rates from gauges that are just over $2 \mathrm{~km}$ apart may show significant differences associated with the strong spatial variability exhibited by rainfall at such time scales. This is clearly illustrated by Fig. 9b. As a consequence, the arithmetic average from such a pair of gauges may not
(A) optical extinction (15-Feb-2006)

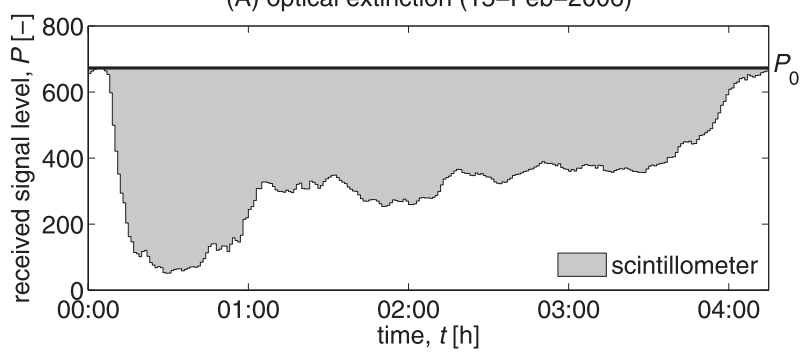

(B) rain rate (15-Feb-2006)

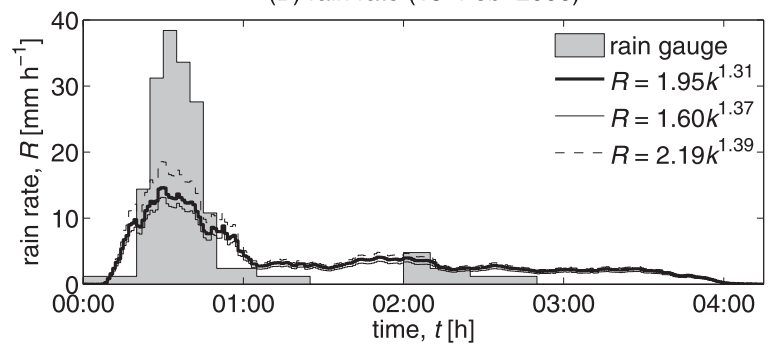

(C) cumulative rain amount (15-Feb-2006)

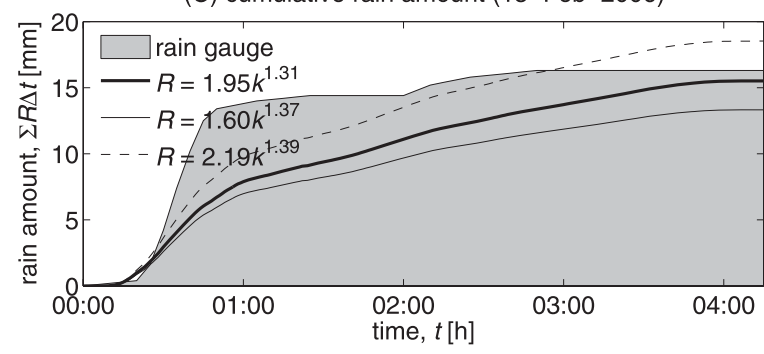

FIG. 8. As in Fig. 3, but for gauge 3 on 15 Feb 2006.

always be representative of the true average rain rate over the scintillometer path (e.g., Villarini et al. 2008).

On the other hand, instrumental effects related to the scintillometer itself may also affect its ability to detect rainfall and infer the associated intensities. During the event on 19 July 2006, the received optical signal is lost completely for a period of more than $10 \mathrm{~min}$ because of the total extinction caused by the heavy rainfall during the most intense precipitation core (as shown by Fig. 10). As a result, the estimated rain rates reach their maximum retrievable values (between 50 and $70 \mathrm{~mm} \mathrm{~h}^{-1}$ for the employed pathlength of $2.4 \mathrm{~km}$, depending on the employed $k-R$ relation), leading to slightly underestimated rain accumulations. This suggests that in order to allow the scintillometer to be able to function properly as a path-average rain gauge in the climate of Benin (i.e., in order to minimize the amount of complete signal loss) the maximum detectable rain rate would need to be increased by reducing the employed pathlength (the distance between transmitter and receiver).

Finally, the strong sensitivity of the received scintillometer signal to raindrops falling through the path between transmitter and receiver can also be used to its 
(A) 5-minute rain rates (15-Feb-2006)

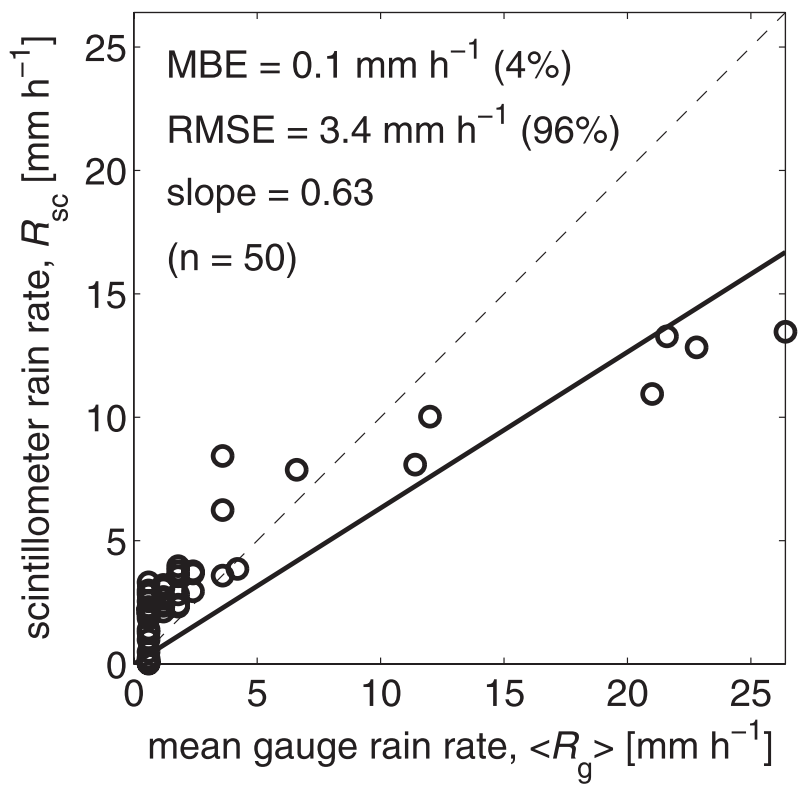

(B) 5-minute rain rates (15-Feb-2006)

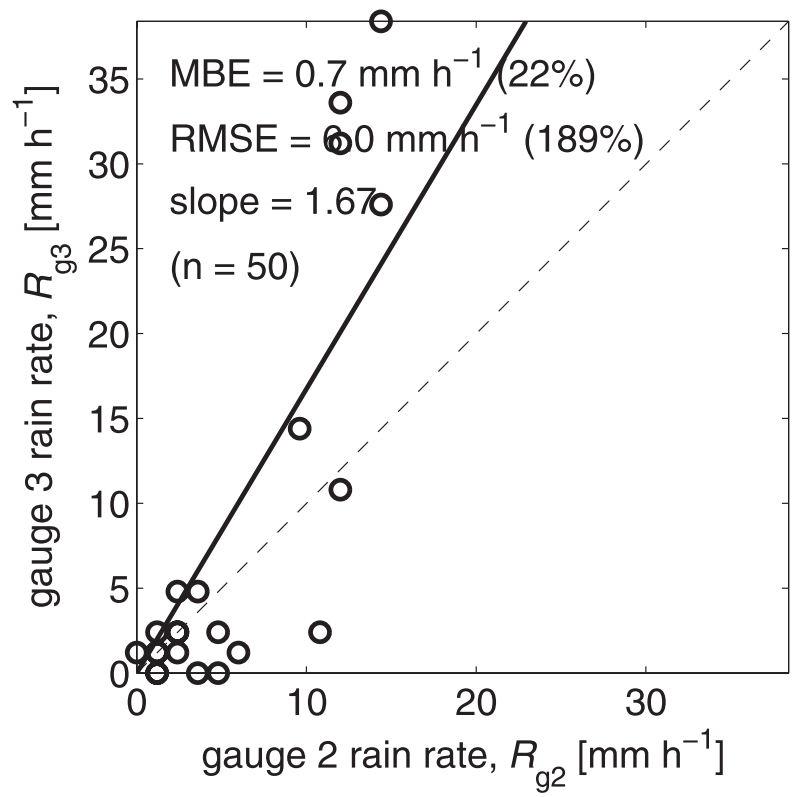

FIG. 9. As in Fig. 5, but for an event on 15 Feb 2006.

advantage. Figure 11 shows that the instrument is ideally suited as a path-average gauge to detect and resolve the dynamics of light rainfall. Where the average rain rate from the two tipping-bucket rain gauges seems to suggest that it rains with a constant intensity of $0.6 \mathrm{~mm} \mathrm{~h}^{-1}$ during $40 \mathrm{~min}$, the scintillometer signal reveals that this event actually exhibits an appreciable amount of temporal variability. Apparently, the event is also characterized by a strong spatial variability, as one rain gauge indicates

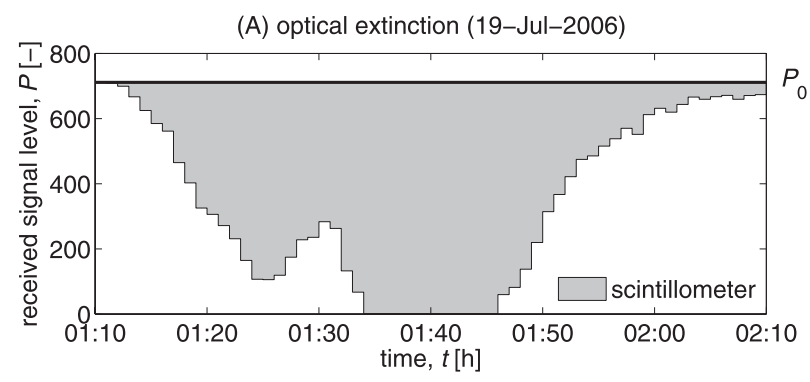

(B) rain rate (19-Jul-2006)

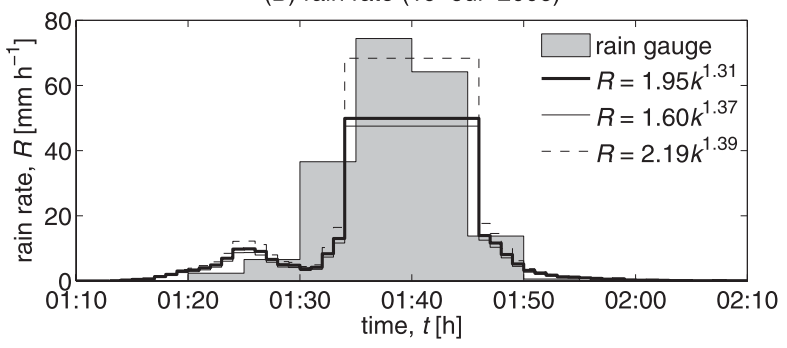

(C) cumulative rain amount (19-Jul-2006)

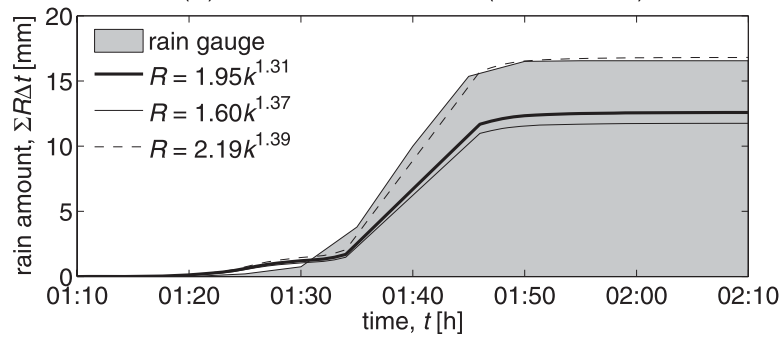

FIG. 10. As in Fig. 3, but for an event on 19 Jul 2006.

a constant rain rate of $1.2 \mathrm{~mm} \mathrm{~h}^{-1}$ (the minimum detectable rain rate for this type of gauge), whereas the other gauge does not detect any rain at all. In other words, the scintillometer is able to detect subtle temporal variations in that part of the rain rate spectrum, namely light rain, where tipping-bucket rain gauges are most prone to sampling errors related to their finite bucket volumes.

\section{c. Potential of scintillometers as path-average rain gauges}

Figure 12 compares the 5-min average rain rates (Fig. 12a) and the total rainfall accumulations per event (Fig. 12b) from the scintillometer with the corresponding averages from the two tipping-bucket rain gauges for all 22 rainfall events considered. Time intervals during which complete loss of the received scintillometer signal occurred have been excluded from this analysis. The overall $k-R$ power law from Table 2 , considered to be representative of the climatological relation for Benin, has been employed to convert path-integrated extinctions to path-average rain rates. Tuning of the $k-R$ power law to obtain the best possible fit of the scintillometer-based 
(A) optical extinction (25-Apr-2006)

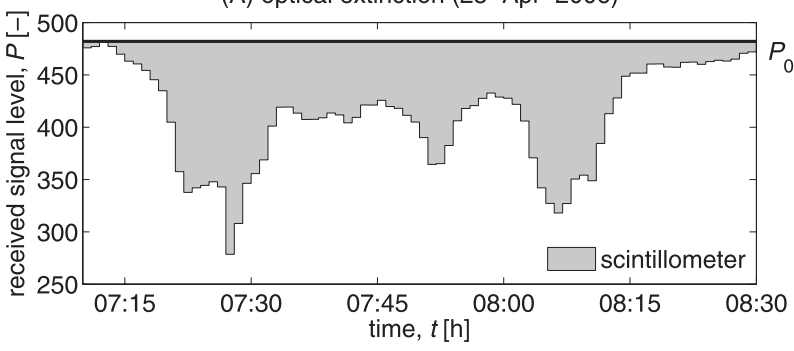

(B) rain rate (25-Apr-2006)

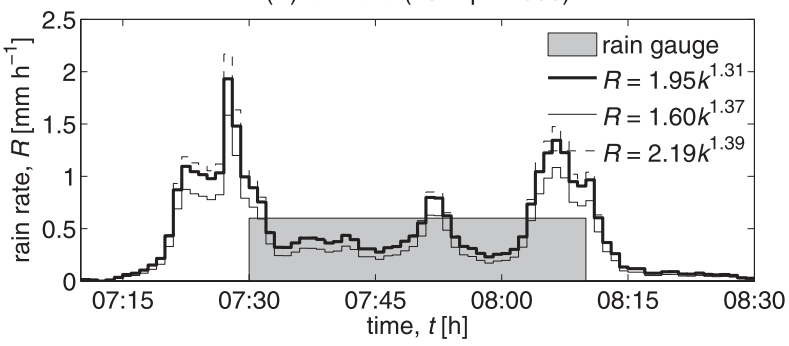

(C) cumulative rain amount (25-Apr-2006)

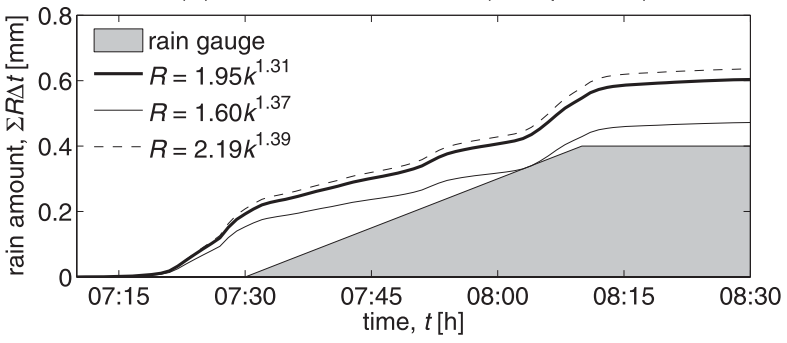

FIG. 11. As in Fig. 3, but for an event on 25 Apr 2006.

rain rates and amounts to those measured by the gauges has not been attempted. Table 3 provides summary statistics of the comparison between scintillometer and rain gauges for all 22 rainfall events considered.

It can be seen that, although there is a clear (linear) correlation between scintillometer and gauges, both in terms of rain rates and in terms of rain amounts, the scintillometer severely underestimates the rain gauges, in particular for larger rain rates (exceeding $15 \mathrm{~mm} \mathrm{~h}^{-1}$ ). This is reflected by the slope of a linear regression through the origin of 0.5 , which can be interpreted as a multiplicative bias of $-50 \%$. At the event scale, this slope increases to 0.77 , corresponding to a reduced—but still appreciable-multiplicative bias of $-23 \%$. For comparison, Fig. 13 shows the same analysis as Fig. 12, but for one of the tipping-bucket rain gauges with respect to the other. Although the mean bias error and root-meansquare error of the gauges among each other are much larger than the errors of the scintillometer with respect to the gauges, both in terms of the rain rates and amounts, the corresponding multiplicative biases, in particular regarding the rain rates, are smaller.
(A) 5-minute rain rates (2006)

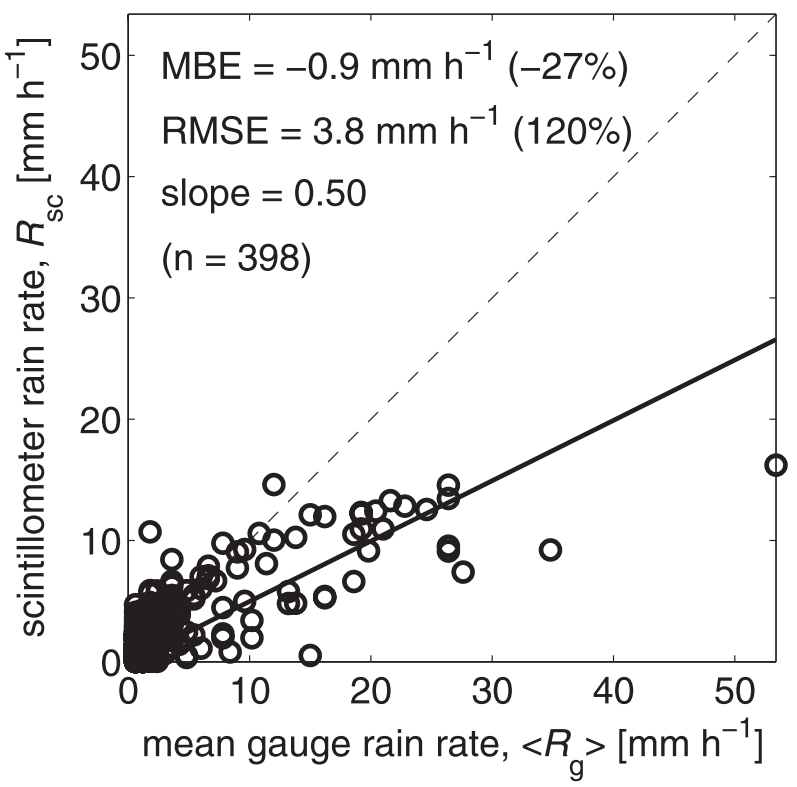

(B) event total rain amounts (2006)

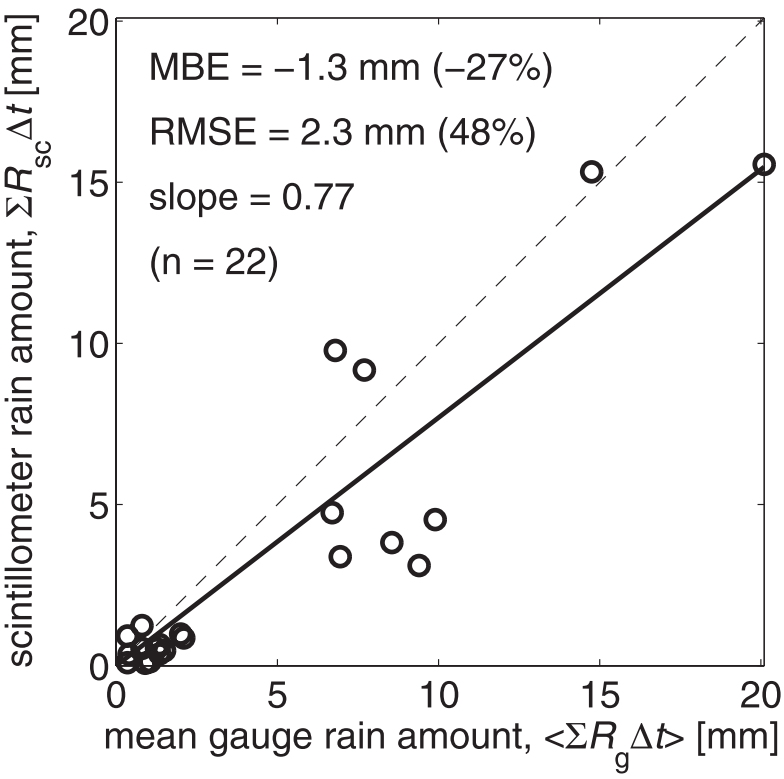

FIG. 12. Comparison of (a) 5-min average rain rates and (b) total rainfall accumulations per event from the scintillometer (using the overall $k-R$ relation from Table 2) with the average from two nearby tipping-bucket rain gauges for all 22 rainfall events considered (excluding the time intervals during which complete loss of the received scintillometer signal occurred). The dashed line indicates the 1:1 line; $\mathrm{MBE}=$ mean bias error, absolute and relative to the mean 5-min gauge rain rate in (a) or to the mean gauge rainfall accumulation per event in (b); RMSE = root-mean-square error, absolute and relative to the mean gauge rain rate in (a) or to the mean gauge rainfall accumulation per event in (b); slope $=$ slope of a linear regression through the origin of the variable on the $y$ axis to that on the $x$ axis (bold line); and $n=$ number of data points. 
TABLE 3. Summary statistics of all 22 rainfall events considered [ 6 events during the dry season (February-April) and 16 events during the rainy season (June-July)]: first column indicates date (in 2006) at which event occurred; subsequent three columns indicate total rainfall accumulations $(\mathrm{mm})$ measured by rain gauge $2\left(\mathrm{G}_{2}\right)$, by gauge $3\left(\mathrm{G}_{3}\right)$, and the average of both gauges $\left(\mathrm{G}_{23}\right)$; subsequent three columns indicate total accumulations $(\mathrm{mm})$ from scintillometer, using overall $k-R$ relation from Table $2\left(\mathrm{Sc}_{\mathrm{All}}\right)$, stratiform relation $\left(\mathrm{Sc}_{\mathrm{Str}}\right)$, and convective relation $\left(\mathrm{Sc}_{\mathrm{Con}}\right)$; final four columns provide comparison of 5-min average rain rates from scintillometer (using overall $k-R$ relation from Table 2) with average of both gauges, where MBE = mean bias error $\left(\mathrm{mm} \mathrm{h}^{-1}\right)$, RMSE $=$ root-mean-square error $\left(\mathrm{mm} \mathrm{h}^{-1}\right)$, slope $=$ slope of linear regression between scintillometer and rain gauges, and $n=$ number of 5-min intervals not prone to complete loss of signal.

\begin{tabular}{|c|c|c|c|c|c|c|c|c|c|c|}
\hline Date & $\mathrm{G}_{2}$ & $\mathrm{G}_{3}$ & $\mathrm{G}_{23}$ & $\mathrm{Sc}_{\mathrm{All}}$ & $\mathrm{Sc}_{\mathrm{Str}}$ & $\mathrm{Sc}_{\mathrm{Con}}$ & MBE & RMSE & Slope & $n$ \\
\hline \multirow[t]{3}{*}{14 Feb } & 1.50 & 0.30 & 0.90 & 0.08 & 0.06 & 0.08 & -3.3 & 3.8 & 0.09 & $3^{*}$ \\
\hline & 8.80 & 8.30 & 8.55 & 3.82 & 3.26 & 4.52 & -2.4 & 5.5 & 0.35 & 24 \\
\hline & 0.00 & 0.70 & 0.35 & 0.10 & 0.07 & 0.09 & -0.4 & 0.1 & 0.28 & 7 \\
\hline $15 \mathrm{Feb}$ & 13.30 & 16.20 & 14.75 & 15.32 & 13.17 & 18.30 & 0.1 & 3.4 & 0.63 & 50 \\
\hline $19 \mathrm{Apr}$ & 5.00 & 8.90 & 6.95 & 3.38 & 2.86 & 3.96 & -2.0 & 4.7 & 0.37 & $21 *$ \\
\hline $25 \mathrm{Apr}$ & 0.00 & 0.80 & 0.40 & 0.35 & 0.28 & 0.37 & -0.1 & 0.3 & 0.89 & 8 \\
\hline 2 Jun & 2.20 & 2.00 & 2.10 & 0.86 & 0.71 & 0.97 & -0.9 & 2.0 & 0.31 & $17^{*}$ \\
\hline 5 Jun & 3.00 & 0.00 & 1.50 & 0.47 & 0.38 & 0.52 & -2.5 & 3.4 & 0.23 & 5 \\
\hline 22 Jun & 0.50 & 2.20 & 1.35 & 0.37 & 0.30 & 0.40 & -0.8 & 0.7 & 0.36 & $14 *$ \\
\hline \multirow[t]{2}{*}{23 Jun } & 0.00 & 2.70 & 1.35 & 0.65 & 0.53 & 0.73 & -0.6 & 0.7 & 0.57 & $13^{*}$ \\
\hline & 4.90 & 13.90 & 9.40 & 3.11 & 2.66 & 3.70 & -3.6 & 5.9 & 0.29 & $21 *$ \\
\hline 29 Jun & 4.90 & 14.90 & 9.90 & 4.53 & 4.01 & 5.62 & -4.6 & 10.3 & 0.37 & $14^{*}$ \\
\hline \multirow[t]{2}{*}{$3 \mathrm{Jul}$} & 0.00 & 2.50 & 1.25 & 0.52 & 0.44 & 0.60 & -0.7 & 0.8 & 0.54 & $13 *$ \\
\hline & 0.20 & 0.50 & 0.35 & 0.92 & 0.81 & 1.14 & 1.4 & 4.2 & 4.16 & $5^{*}$ \\
\hline $6 \mathrm{Jul}$ & 2.90 & 1.10 & 2.00 & 0.98 & 0.81 & 1.11 & -0.8 & 1.6 & 0.44 & 16 \\
\hline 14 Jul & 0.00 & 1.60 & 0.80 & 0.54 & 0.46 & 0.64 & -1.6 & 6.0 & 0.37 & 2 \\
\hline \multirow[t]{3}{*}{$15 \mathrm{Jul}$} & 0.00 & 2.10 & 1.05 & 0.12 & 0.10 & 0.14 & -1.0 & 0.4 & 0.12 & $11 *$ \\
\hline & 6.80 & 8.60 & 7.70 & 9.17 & 7.82 & 10.84 & 0.4 & 1.2 & 1.01 & 42 \\
\hline & 9.40 & 4.00 & 6.70 & 4.75 & 4.17 & 5.84 & -2.6 & 5.3 & 0.61 & 9 \\
\hline 17 Jul & 1.30 & 12.30 & 6.80 & 9.78 & 8.26 & 11.42 & 0.8 & 1.5 & 1.33 & $45^{*}$ \\
\hline 19 Jul & 1.10 & 0.50 & 0.80 & 1.24 & 1.07 & 1.50 & 1.8 & 1.5 & 1.25 & $3^{*}$ \\
\hline $20 \mathrm{Jul}$ & 18.90 & 21.30 & 20.10 & 15.55 & 13.42 & 18.69 & -1.0 & 2.8 & 0.65 & $55^{*}$ \\
\hline
\end{tabular}

* Events for which at least one time interval with complete loss of signal was excluded from the analysis.

There are several possible explanations for the observed underestimation of the rainfall derived from the scintillometer with respect to that from the tippingbucket gauges:

- The employed "climatological" $k-R$ relation may not be appropriate for certain events, such as that on 14 February 2006 (Fig. 6), because it is not representative of the ambient microphysical conditions (i.e., the space-time variation of the raindrop size distribution).

- Because of the strong spatial variability of rainfall at a spatial scale of the order of two kilometers and a temporal scale of the order of five minutes, the arithmetic average of two-point measurements from rain gauges located a few hundreds of meters away from the scintillometer path may not be representative of the path-average rain rate estimated from the scintillometer (e.g., Villarini et al. 2008).

- Multiple scattering during intense rainfall, an effect not accounted for by Eq. (2), could lead to increased forward scattering and therefore to a decrease in the measured path-integrated extinction (e.g., Tam 1980; van de Hulst 1981; Tam and Zardecki 1982; Zardecki and Tam 1982). Zardecki and Tam (1982) argue that "multiple scattering corrections are significant for rainfall rates of 12.5 and $25 \mathrm{~mm} \mathrm{~h}^{-1}$." However, their calculations are based on the exponential family of raindrop size distributions according to Marshall and Palmer (1948), which contains a much larger concentration of small droplets as compared to the gamma raindrop size distributions with a fixed $\mu$ parameter of 5.5 typically encountered in Benin (Moumouni et al. 2008). As a result, the optical extinction at a given rain rate will be much smaller in Benin than that calculated on the basis of the Marshall-Palmer distribution. This is clearly illustrated by Fig. 4 , where the lower boundary of the gray area represents the $k-R$ power law based on the Marshall-Palmer distribution. In conclusion, except for very high rain rates, the underestimation of the extinction due to multiple scattering is expected to be only of the order of about 10\% (Zardecki and Tam 1982) for the relatively lowdensity rainfall typically encountered in Benin (associated with a deficit of otherwise abundant small droplets) as well as the limited pathlength of only $2.4 \mathrm{~km}$ 
- Given a point-scale $k-R$ power-law relation with an exponent larger than one (such as the relations in Tables 1 and 2), the "effective" power law between the space-time average of $R$ and that of $k$ is such that the inferred rain rate for a given specific extinction becomes larger than the rain rate obtained using the point-scale relation, which could lead to an underestimation of inferred path-average rain rates if space-time rainfall variability is not explicitly accounted for. This can be seen by expanding $R=(k / c)^{1 / d}$ in a Taylor series around the mean of $k,\langle k\rangle$, and neglecting all terms of third order and higher. This leads to an adjusted form of Eq. (3), namely

$$
\langle R\rangle=\left[1+\frac{1}{2 d}\left(\frac{1}{d}-1\right) \mathrm{CV}_{k}^{2}\right]\left(\frac{\langle k\rangle}{c}\right)^{1 / d},
$$

where $\mathrm{CV}_{k}$ is the coefficient of variation of $k$ along the scintillometer path. Obviously, this second-order Taylor series expansion is only accurate for small-tomoderate values of $\mathrm{CV}_{k}$. The factor between the square brackets acts as a correction to the coefficient $(1 / c)^{1 / d}$ of the point-scale $k-R$ power-law relation. Note that the exponent $1 / d$ remains unaffected by the upscaling operation. Clearly, if rainfall along the scintillometer path is constant, then $\mathrm{CV}_{k}=0$, and the correction factor reduces to 1 (i.e., no correction), independent of the exponent of the power-law $k-R$ relation. The same occurs if the $k-R$ relation is linear (i.e., $1 / d=1$ ), independent of rainfall variations along the scintillometer path. Figure 14 shows that the correction factor can amount to several dozens of percent, depending on the value of $\mathrm{CV}_{k}$, which could partially explain the observed underestimation of the rainfall derived from the scintillometer with respect to that from the tipping-bucket gauges.

Although a detailed treatment of these issues is beyond the scope of the current study, which is in essence merely "a proof of concept," a few additional analyses will shed some light on their potential effects.

Figure 12a suggests that for smaller rain rates (less than $\sim 15 \mathrm{~mm} \mathrm{~h}^{-1}$ ) the observed bias of the scintillometer with respect to the tipping-bucket rain gauges is actually much less prominent than for larger rain rates. This is confirmed by Fig. 15, which provides a closer look at this part of Fig. 12, zooming into rain rates smaller than $20 \mathrm{~mm} \mathrm{~h}^{-1}$ (Fig. 15a) and $10 \mathrm{~mm} \mathrm{~h}^{-1}$ (Fig. 15b). Note that these selections still contain 386 and 364 of the original 398 (Fig. 12a) 5-min intervals-that is, the large majority (97\% and $91 \%$, respectively). Both selections significantly reduce the mean bias error, root-meansquare error, and multiplicative bias. Limiting the analysis
(A) 5-minute rain rates (2006)

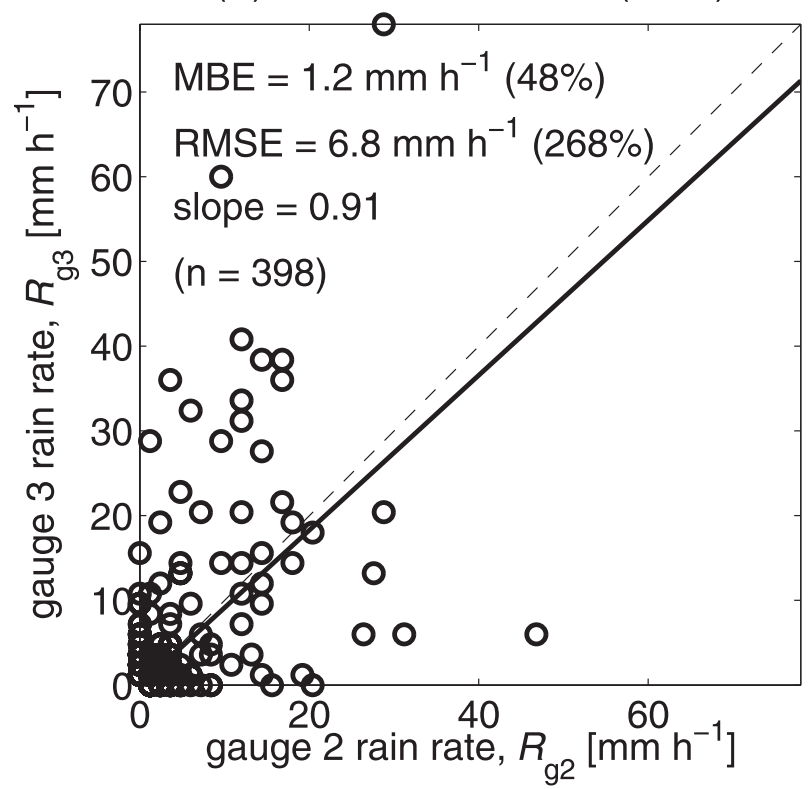

(B) event total rain amounts (2006)

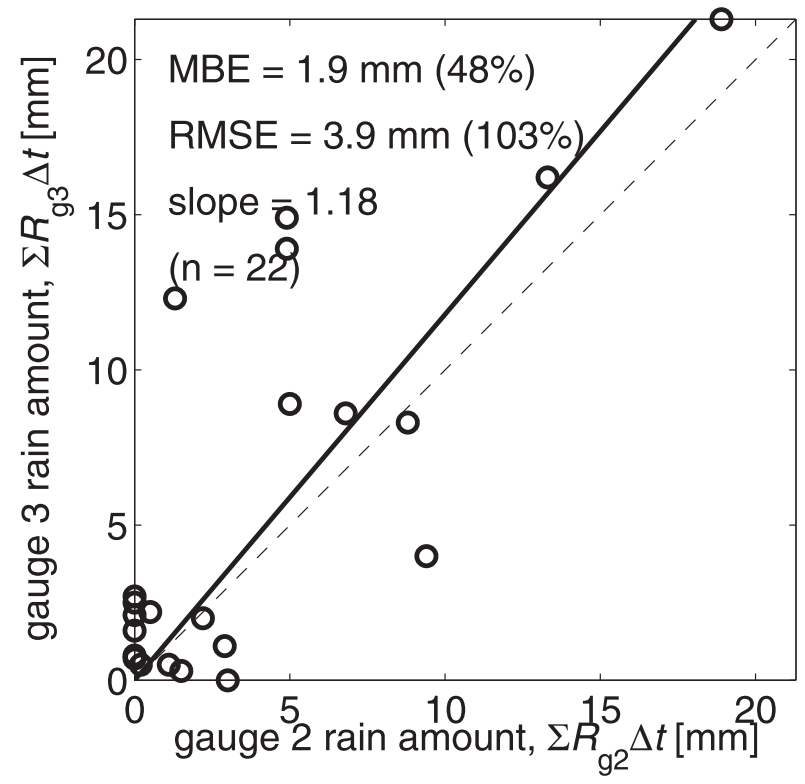

FIG. 13. As in Fig. 12, but for gauge 3 with respect to gauge 2.

to rain rates smaller than $10 \mathrm{~mm} \mathrm{~h}^{-1}$ even completely removes the (additive) mean bias error and reduces the multiplicative bias to $-13 \%$. In summary, the observed underestimation of the rainfall derived from the scintillometer with respect to that from the tipping-bucket gauges is largely contained in the less than $10 \%$ of the time during which rain rates exceed $10 \mathrm{~mm} \mathrm{~h}^{-1}$.

It was previously suggested that application of a pointscale $k-R$ power-law relation to averages of $R$ and $k$ without explicitly accounting for the space-time rainfall 


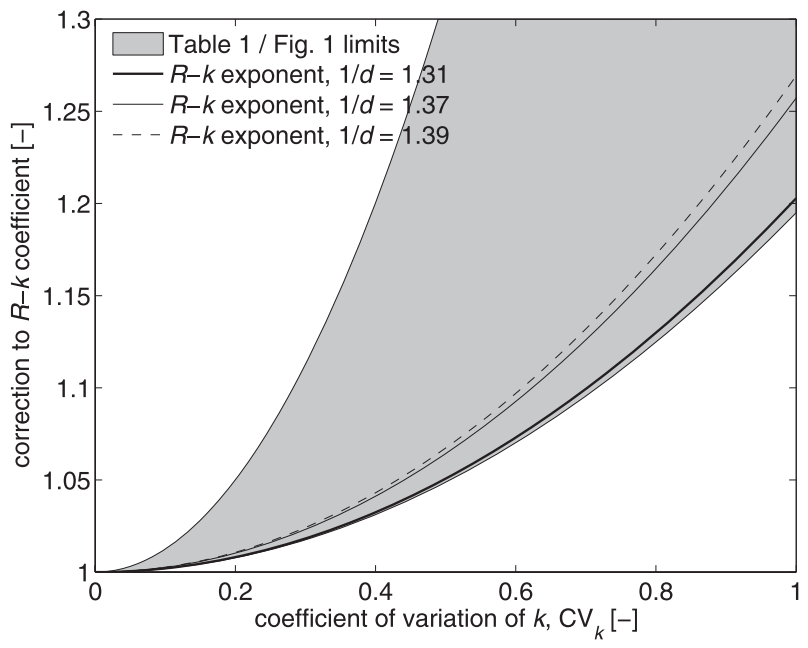

FIG. 14. Correction factor for the coefficient of the point-scale $k-R$ power-law relation [the factor between square brackets in Eq. (15)] as a function of the coefficient of variation of $k$ along the scintillometer path and the value of the exponent of the power-law relation (Table 2). The gray area represents the range of $k-R$ exponents $(1.30-2.16)$ from Table 1 and Fig. 1.

variability may lead to an underestimation of the inferred path-average rain rates. The stronger the rainfall variability, the larger the resulting underestimation would be. A quantitative analysis of this effect would require consideration of the spatial correlation structure of rainfall, which is clearly beyond reach given the current experimental setup with only two rain gauges over the 2.4-km scintillometer path. Berne and Uijlenhoet (2007) and Leijnse et al. $(2008,2010)$ present simulation studies of this issue for the case of rainfall estimation using microwave links, which could potentially be extended to infrared and optical wavelengths.

Nevertheless, even with only two gauges it is possible to obtain a rough idea of the spatial variability of rainfall. For this purpose, we employ the absolute difference between the 5-min average rain rates from the two gauges (about $2 \mathrm{~km}$ apart) as a measure of the spatial rainfall variability along the scintillometer path. Figure 16a indeed shows that the underestimation of the 5-min average rain rates by the scintillometer with respect to the rain gauges systematically increases as a function of the absolute difference between the two gauges. Limiting the absolute gauge difference to values smaller than $5 \mathrm{~mm} \mathrm{~h}^{-1}$ (Fig. 16b) effectively removes the (additive) mean bias error and reduces the multiplicative bias to $-20 \%$. Note that this selection still contains 350 of the original 398 (Fig. 12a) 5-min intervals (i.e., 88\%).

Finally, we return to the issue of the complete loss of the received signal, which may occur because of heavy rainfall along the scintillometer path (e.g., Figure 10).

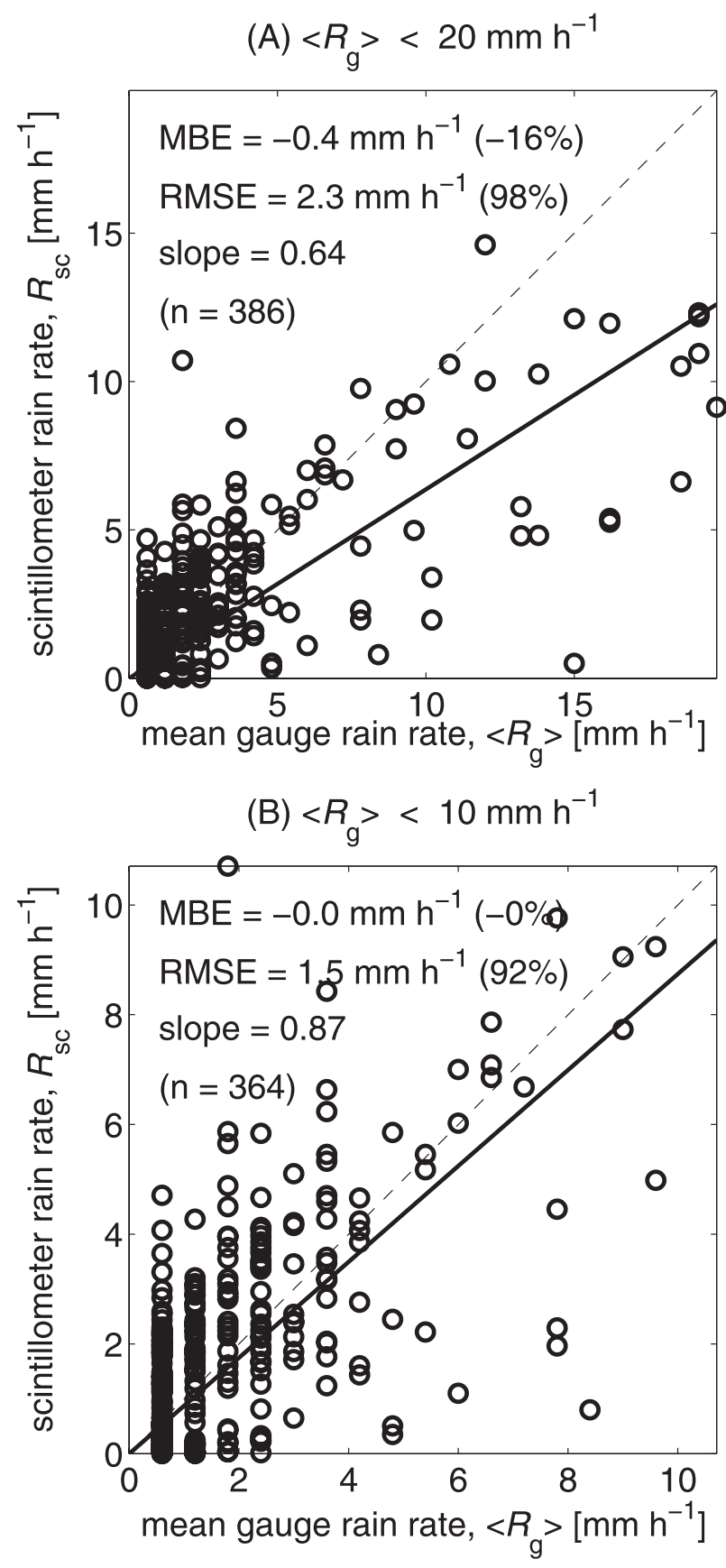

FIG. 15. As in Fig. 12a, but limiting the maximum 5-min average gauge rain rate to (a) 20 and (b) $10 \mathrm{~mm} \mathrm{~h}^{-1}$.

One way to reduce the probability of occurrence of this phenomenon would be to decrease the employed pathlength from transmitter to receiver (e.g., from the current $2.4 \mathrm{~km}$ to say $1 \mathrm{~km}$ ). Figure 17 a shows the maximum retrievable rain rate-that is, the maximum detectable rain rate before complete loss of the received signal would occur-for the three $k-R$ power laws presented in 

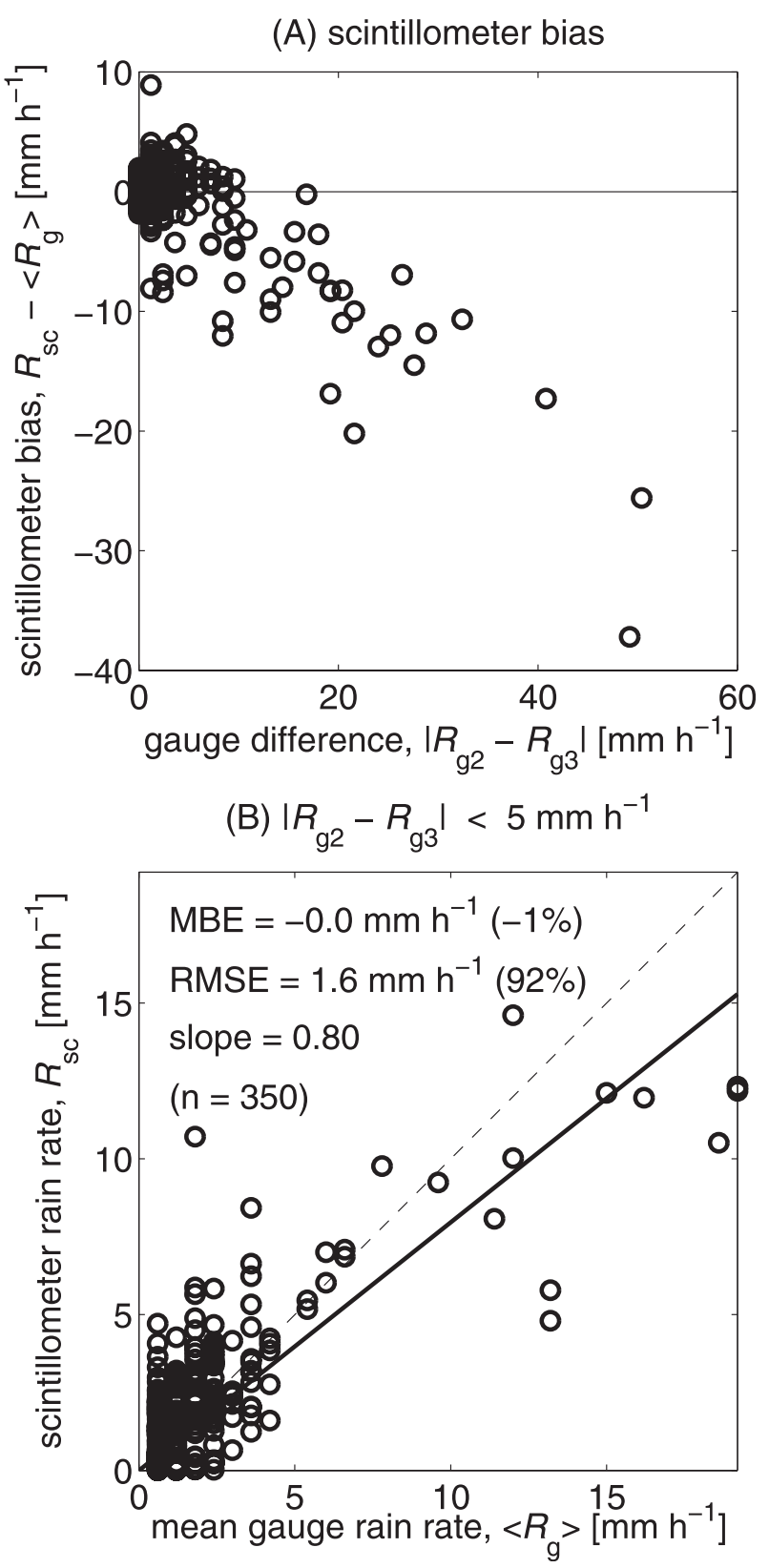

FIG. 16. (a) Bias in the 5-min average rain rates from the scintillometer (using the overall $k-R$ relation from Table 2) with respect to the mean of the 5-min average rain rates from two nearby tipping-bucket rain gauges as a function of the absolute difference between the rain rates from the two gauges. (b) Same as Fig. 12a, but limiting the maximum absolute gauge difference to $5 \mathrm{~mm} \mathrm{~h}^{-1}$.

Table 2 as a function of the signal base level $P_{0}$. It can be seen that, for the typically encountered signal base levels during the events discussed above, reducing the employed pathlength from 2.4 to $1 \mathrm{~km}$ would yield an increase of the maximum detectable rain rate from $\sim 50$ to $\sim 150 \mathrm{~mm} \mathrm{~h}^{-1}$, which would be more than enough
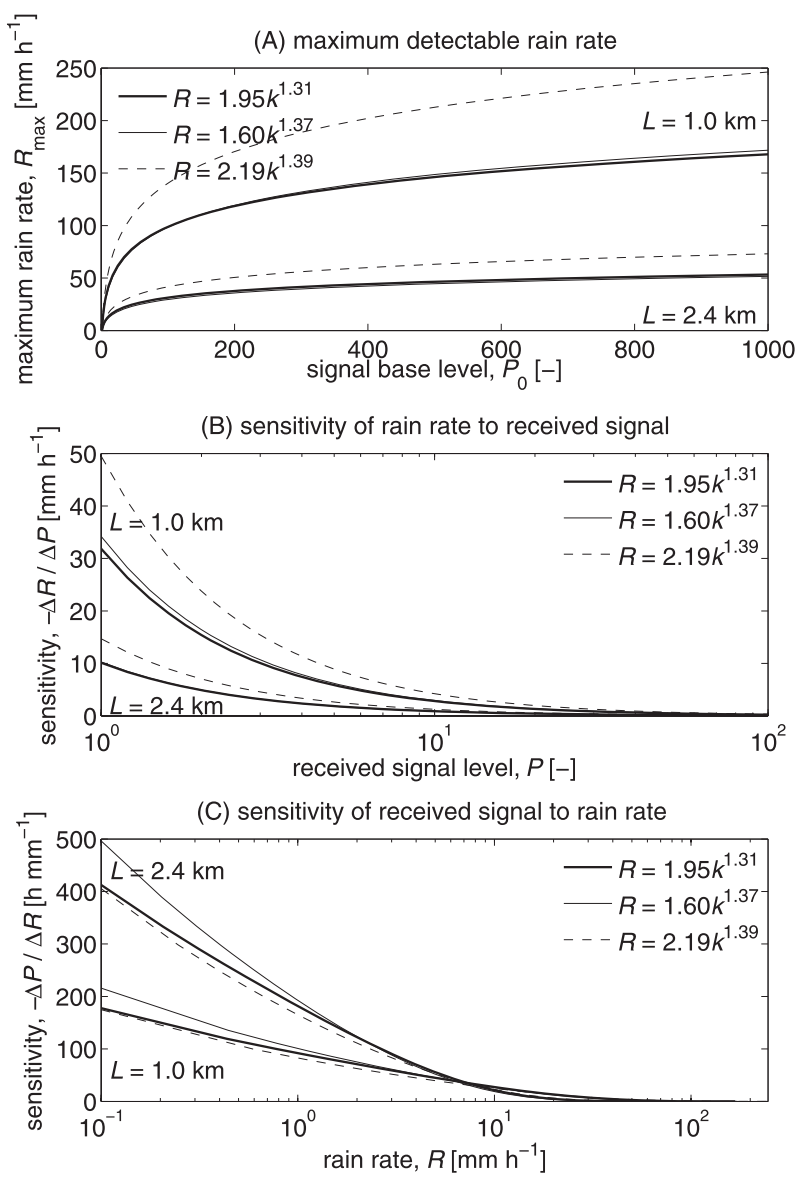

FIG. 17. The maximum retrievable rain rate (before complete loss of the received scintillometer signal occurs) as a function of (a) the signal base level $P_{0}$, (b) the sensitivity of the retrieved rain rate to the received signal level $P$, and the (c) sensitivity of the received signal level to the rain rate along the scintillometer path. The different lines correspond to the $3 k-R$ power laws presented in Table 2 (bold line: all, solid line: convective, and dashed line: stratiform). The 2 triplets correspond to 2 pathlengths $L$ (1.0 and $2.4 \mathrm{~km})$.

for all practical purposes. An additional advantage of a shorter pathlength would be a reduced effect of spatial rainfall variability along the scintillometer path. A minor drawback could be the slightly decreased sensitivity of the scintillometer to variations in the pathaverage rain rate (Figs. $17 b, c)$.

\section{Conclusions and perspectives}

A comparison of rainfall estimates from a largeaperture scintillometer over a $2.4-\mathrm{km}$ path with measurements from two nearby rain gauges for 22 events yields promising results: 5 -min rain rates and event total rain amounts estimated using the scintillometer are 
within $20 \%$ of those estimated using the rain gauges if an appropriate $k-R$ relation is employed and if the time during which the signal is lost completely remains limited. If the pathlength would be limited to $1 \mathrm{~km}$, such power losses are unlikely to occur, even for rain rates exceeding $150 \mathrm{~mm} \mathrm{~h}^{-1}$.

Measurements of the temporal fine structure of rainfall at the spatial scale of scintillometers (which is on the order of mesoscale meteorological models) could potentially be employed to discriminate between different types of precipitation (e.g., stratiform and convective). We are currently carrying out further comparisons with high-resolution rain gauges, a disdrometer (the one employed by Moumouni et al. 2008, located at a distance of about $7 \mathrm{~km}$ from the scintillometer path), and a rain radar to study this issue in greater detail.

The obtained results demonstrate the potential of largeaperture scintillometers to estimate the path-average precipitation intensity when it rains and the path-average sensible heat flux when it is dry (as in Guyot et al. 2009, who employed the same dataset as is used in this article). As such, this work complements earlier investigations, where we have demonstrated the combined use of microwave links as (radio wave) boundary layer scintillometers for the estimation of the path-average latent heat flux (evaporation) and as path-average rain gauges (Leijnse et al. 2007a,b). The combined use of largeaperture and radio-wave scintillometers has been proposed for the estimation of both sensible and latent heat flux, independent of measurements of net radiation and soil heat flux (Kohsiek and Herben 1983; Meijninger et al. 2002a, 2006). Such a combined setup has potential for path-average rainfall estimation as well, being much less sensitive to variations in drop size distributions than separate optical or microwave links. This is a topic of ongoing research.

Acknowledgments. The first author acknowledges the comments and suggestions of his colleagues Hidde Leijnse and Han Stricker concerning an earlier draft of this paper, as well as funding from the Netherlands Organization for Scientific Research (NWO) in the framework of the Water Programme. Based on a French initiative, AMMA was built by an international scientific group and is currently funded by a large number of agencies, especially from France, the United Kingdom, the United States, and Africa. It has been the beneficiary of a major financial contribution from the European Community's Sixth Framework Research Programme. Detailed information on scientific coordination and funding is available on the AMMA International web site (http://www.amma-international.org).

\section{APPENDIX}

\section{$\boldsymbol{k}-\boldsymbol{R}$ Relations from $\boldsymbol{Z}-\boldsymbol{R}$ Relations}

The radar reflectivity factor $Z\left(\mathrm{~mm}^{6} \mathrm{~m}^{-3}\right)$ is defined as the sixth-order moment of the raindrop size distribution

$$
Z=\int_{0}^{\infty} D^{6} N(D) d D
$$

We assume that $N(D)$ obeys the scaling law of Eq. (8) and $g(x)$ follows the gamma form $\kappa x^{\mu} \exp (-\lambda x)$. Substitution of Eq. (8) into Eq. (A1) leads to the power-law relation

$$
Z=a R^{b}
$$

with coefficient

$$
a=\int_{0}^{\infty} x^{6} g(x) d x=\frac{\kappa \Gamma(7+\mu)}{\lambda^{7+\mu}}
$$

and exponent

$$
b=\alpha+7 \beta=1+(3-\gamma) \beta
$$

(Uijlenhoet 2008). For a fixed value of $\mu$, which for the AMMA dataset was found to be about 5.5 (Moumouni et al. 2008), Eqs. (A3) and (A4) and the constraints [Eqs. (9) and (11)] can now be employed to infer the values of the parameters $\kappa$ and $\lambda$ and the scaling exponents $\alpha$ and $\beta$. These values can subsequently be substituted in Eqs. (13) and (14) to estimate the coefficient and exponent of the corresponding power-law $k-R$ relation.

\section{REFERENCES}

Atlas, D., 1953: Optical extinction by rainfall. J. Meteor., 10, 486488.

_ and C. W. Ulbrich, 1977: Path- and area-integrated rainfall measurement by microwave attenuation in the $1-3 \mathrm{~cm}$ band. J. Appl. Meteor., 16, 1322-1331.

Battan, L. J., 1973: Radar Observation of the Atmosphere. The University of Chicago Press, $324 \mathrm{pp}$.

Beard, K. V., 1976: Terminal velocity of cloud and precipitation drops aloft. J. Atmos. Sci., 33, 851-864.

Berne, A., and R. Uijlenhoet, 2007: Path-averaged rainfall estimation using microwave links: Uncertainty due to spatial rainfall variability. Geophys. Res. Lett., 34, L07403, doi:10.1029/ 2007GL029409.

Beyrich, F., H. A. R. de Bruin, W. M. L. Meijninger, and F. Schipper, 2002: Experiences from one-year continuous operation of a large aperture scintillometer over a heterogeneous land surface. Bound.-Layer Meteor., 105, 85-97. 
Bradley, S. G., C. D. Stow, and C. A. Lynch-Blosse, 2000: Measurements of rainfall properties using long optical path imaging. J. Atmos. Oceanic Technol., 17, 761-772.

Cain, J. D., P. T. W. Rosier, W. Meijninger, and H. A. R. de Bruin, 2001: Spatially averaged sensible heat fluxes measured over barley. Agric. For. Meteor., 107, 307-322.

Chehbouni, A., and Coauthors, 1999: Estimation of area-average sensible heat flux using a large-aperture scintillometer during the Semi-Arid Land-Surface-Atmosphere (SALSA) Experiment. Water Resour. Res., 35, 2505-2511.

Chýlek, P., 1977: A note on extinction and scattering efficiencies. J. Appl. Meteor., 16, 321-322.

de Bruin, H. A. R., B. J. J. M. van den Hurk, and W. Kohsiek, 1995: The scintillation method tested over a dry vineyard area. Bound.-Layer Meteor., 76, 25-40.

Deirmendjian, D., 1975: Far-infrared and sub-millimeter wave attenuation by clouds and rain. J. Appl. Meteor., 14, 15841593.

Guyot, A., J.-M. Cohard, S. Anquetin, S. Galle, and C. R. Lloyd, 2009: Combined analysis of energy and water balances to estimate latent heat flux of a Sudanian small catchment. $J$. Hydrol., 375, 227-240, doi:10.1016/j.jhydrol.2008.12.027.

Kohsiek, W., and M. H. A. J. Herben, 1983: Evaporation derived from optical and radio wave scintillation. Appl. Opt., 22, 25662569.

Lagouarde, J.-P., J.-M. Bonnefond, Y. H. Kerr, K. J. McAneney, and M. Irvine, 2002: Integrated sensible heat flux measurements of a two-surface composite landscape using scintillometry. Bound.-Layer Meteor., 105, 4-37.

Laws, J. O., and D. A. Parsons, 1943: The relation of raindrop size to intensity. Trans. Amer. Geophys. Union, 24, 452-460.

Leijnse, H., R. Uijlenhoet, and J. N. M. Stricker, 2007a: Hydrometeorological application of a microwave link: 1. Evaporation. Water Resour. Res., 43, W04416, doi:10.1029/2006WR004988.

,$- \longrightarrow$, and 2007b: Hydrometeorological application of a microwave link: 2. Precipitation. Water Resour. Res., 43, W04417, doi:10.1029/2006WR004989.

_ — - and _ 2008: Microwave link rainfall estimation: Effects of link length and frequency, temporal sampling, power resolution, and wet antenna attenuation. Adv. Water Resour., 31, 1481-1493, doi:10.1016/j.advwatres.2008.03.004.

,$- \ldots$, and A. Berne, 2010: Errors and uncertainties in microwave link rainfall estimation explored using drop size measurements and high-resolution radar data. J. Hydrometeor., 11, 1330-1344.

Marshall, J. S., and W. M. Palmer, 1948: The distribution of raindrops with size. J. Meteor., 5, 165-166.

Meijninger, W. M. L., and H. A. R. de Bruin, 2000: The sensible heat fluxes over irrigated areas in western Turkey determined with a large aperture scintillometer. J. Hydrol., 229, 42-49.

, A. E. Green, O. K. Hartogensis, W. Kohsiek, J. C. B. Hoedjes, R. M. Zuurbier, and H. A. R. de Bruin, 2002a: Determination of area-averaged water vapour fluxes with large aperture and radio wave scintillometers over a heterogeneous surface-Flevoland field experiment. Bound.-Layer Meteor., 105, 63-83.

—, O. K. Hartogensis, W. Kohsiek, J. C. B. Hoedjes, R. M. Zuurbier, and H. A. R. de Bruin, 2002b: Determination of area-averaged sensible heat fluxes with a large aperture scintillometer over a heterogeneous surface-Flevoland field experiment. Bound.-Layer Meteor., 105, 37-62.

, F. Beyrich, A. Lüdi, W. Kohsiek, and H. A. R. de Bruin, 2006: Scintillometer-based turbulent fluxes of sensible and latent heat over a heterogeneous land surface-A contribution to LITFASS-2003. Bound.-Layer Meteor., 121, 89-110, doi:10.1007/ s10546-005-9022-8

Moumouni, S., M. Gosset, and E. Houngninou, 2008: Main features of rain drop size distributions observed in Benin, West Africa, with optical disdrometers. Geophys. Res. Lett., 35, L23807, doi:10.1029/2008GL035755.

Nedvidek, F. J., Z. Kucerovsky, and E. Brannen, 1983: An instrument for the measurement of precipitation rate by near-infrared extinction. J. Climate Appl. Meteor., 22, 1581-1586.

— C. W. Schneider, Z. Kucerovsky, and E. Brannen, 1986: Nearinfrared extinction in rain measured using a single detector system. J. Atmos. Oceanic Technol., 3, 391-399.

Olsen, R. L., D. V. Rogers, and D. B. Hodge, 1978: The $a R^{b}$ relation in the calculation of rain attenuation. IEEE Trans. Antennas Propag., 26, 318-329.

Salles, C., J.-D. Creutin, and D. Sempere Torres, 1998: The optical spectropluviometer revisited. J. Atmos. Oceanic Technol., 15, 1215-1222.

Scintec, 2004: Boundary Layer Scintillometer User's Manual, Version 1.28. Scintec AG, $60 \mathrm{pp}$.

Sempere Torres, D., J. M. Porrà, and J.-D. Creutin, 1994: A general formulation for raindrop size distribution. J. Appl. Meteor., 33, 1494-1502.

,-- , and -1998 : Experimental evidence of a general description for raindrop size distribution properties. J. Geophys. Res., 103, 1785-1797.

Shipley, S. T., E. W. Eloranta, and J. A. Weinman, 1974: Measurement of rainfall rates by lidar. J. Appl. Meteor., 13, 800807.

Stow, C. D., S. G. Bradley, K. Paulson, and L. Couper, 1991: The simultaneous measurement of rainfall intensity, drop-size distribution, and the scattering of visible light. J. Appl. Meteor., 30, 1422-1435.

Tam, W. G., 1980: Multiple scattering corrections for atmospheric aerosol extinction measurements. Appl. Opt., 19, 2090-2092.

- and A. Zardecki, 1982: Multiple scattering corrections to the Beer-Lambert law: I. Open detector. Appl. Opt., 21, 24052412

Thurai, M., and V. N. Bringi, 2005: Drop axis ratios from a 2D video disdrometer. J. Atmos. Oceanic Technol, 22, 966978.

Uijlenhoet, R., 2008: Precipitation physics and rainfall observation. Climate and the Hydrological Cycle, M. F. P. Bierkens, P. A. Troch, and A. J. Dolman, Eds., IAHS Press, 59-97.

_ , and J. N. M. Stricker, 1999: A consistent rainfall parameterization based on the exponential raindrop size distribution. J. Hydrol., 218, 101-127.

_ J. A. Smith, and M. Steiner, 2003a: The microphysical structure of extreme precipitation as inferred from groundbased raindrop spectra. J. Atmos. Sci., 60, 1220-1238.

_, M. Steiner, and J. A. Smith, 2003b: Variability of raindrop size distributions in a squall line and implications for radar rainfall estimation. J. Hydrometeor., 4, 43-61.

- J. M. Porrà, D. Sempere Torres, and J.-D. Creutin, 2006: Analytical solutions to sampling effects in drop size distribution measurements during stationary rainfall: Estimation of bulk rainfall variables. J. Hydrol., 328, 65-82, doi:10.1016/ j.jhydrol.2005.11.043.

Ulbrich, C. W., and D. Atlas, 1985: Extinction of visible and infrared radiation in rain: Comparison of theory and experiment. J. Atmos. Oceanic Technol., 2, 331-339. 
van de Hulst, H. C., 1981: Light Scattering by Small Particles. Dover, $470 \mathrm{pp}$.

Villarini, G., P. V. Mandapaka, W. F. Krajewski, and R. Moore, 2008: Rainfall and sampling uncertainties: A rain gauge perspective. J. Geophys. Res., 113, D11102, doi:10.1029/ 2007JD009214.

Wang, T.-I., and S. F. Clifford, 1975: Use of rainfall-induced optical scintillations to measure path-averaged rain parameters. J. Opt. Soc. Amer., 65, 927-937.
_ , G. R. Ochs, and S. F. Clifford, 1978: A saturation-resistant optical scintillometer to measure $C_{n}^{2}$.J. Opt. Soc. Amer., 68, 334-338.

_, K. B. Earnshaw, and R. S. Lawrence, 1979: Path-averaged measurements of rain rate and raindrop size distribution using a fast-response optical sensor. J. Appl. Meteor., 18, 654-660.

Zardecki, A., and W. G. Tam, 1982: Multiple scattering corrections to the Beer-Lambert law: II. Detector with a variable field of view. Appl. Opt., 21, 2413-2420. 